\title{
Physical properties of the Mars Exploration Rover landing sites as inferred from Mini-TES-derived thermal inertia
}

\author{
Robin L. Fergason, ${ }^{1}$ Philip R. Christensen, ${ }^{1}$ James F. Bell III, ${ }^{2}$ Matthew P. Golombek, ${ }^{3}$ \\ Kenneth E. Herkenhoff, ${ }^{4}$ and Hugh H. Kieffer ${ }^{5}$
}

Received 1 September 2005; revised 28 October 2005; accepted 8 November 2005; published 11 February 2006.

[1] The Miniature Thermal Emission Spectrometer (Mini-TES) on board the two Mars Exploration Rovers provides the first opportunity to observe thermal properties from the Martian surface, relate these properties to orbital data, and perform soil conductivity experiments under Martian conditions. The thermal inertias of soils, bedforms, and rock at each landing site were derived to quantify the physical properties of these features and understand geologic processes occurring at these localities. The thermal inertia for the Gusev plains rock target Bonneville Beacon $\left(\sim 1200 \mathrm{~J} \mathrm{~m}^{-2} \mathrm{~K}^{-1} \mathrm{~s}^{-1 / 2}\right)$ is consistent with a dense, basaltic rock, but the rocks at the Columbia Hills have a lower thermal inertia $\left(\sim 620 \mathrm{~J} \mathrm{~m}^{-2} \mathrm{~K}^{-1} \mathrm{~s}^{-1 / 2}\right)$, suggesting that they have a volcaniclasic origin. Bedforms on the floors of craters at both landing sites have thermal inertias of $200 \mathrm{~J} \mathrm{~m}^{-2} \mathrm{~K}^{-1} \mathrm{~s}^{-1 / 2}$, consistent with a particle diameter of $\sim 160 \mu \mathrm{m}$. This diameter is comparable to the most easily moved grain size in the current atmosphere on Mars, suggesting that these bedforms may have formed under current atmospheric conditions. Along the Meridiani plains, the thermal inertia is lower than that derived from TES and Thermal Emission Imaging System (THEMIS) orbital data. This discrepancy is not well understood. Mini-TES-derived thermal inertias at Gusev along a $\sim 2.5 \mathrm{~km}$ traverse follow trends in thermal inertia measured from orbit with TES and THEMIS. However, along the traverse, there are variability and mixing of particle sizes that are not resolved in the orbital thermal inertia data due to meter-scale processes that are not identifiable at larger scales.

Citation: Fergason, R. L., P. R. Christensen, J. F. Bell III, M. P. Golombek, K. E. Herkenhoff, and H. H. Kieffer (2006), Physical properties of the Mars Exploration Rover landing sites as inferred from Mini-TES-derived thermal inertia, J. Geophys. Res., 111, E02S21, doi:10.1029/2005JE002583.

\section{Introduction}

[2] An important science goal of the Mars Exploration Rover (MER) mission is to identify and understand current processes acting on the Martian surface and how they have shaped the morphology in recent history. Thermal inertia is an important tool for understanding recent processes because it provides a means to quantify surface physical characteristics, such as particle size, clast abundance, and rock porosity or degree of weathering. This measurement also allows for quantitative comparisons between the MER sites. In addition, calculating thermal inertia at the MER sites is important for improving the interpretation of orbitally derived thermal inertias, increasing the confidence in the orbital measurements, and extending the

\footnotetext{
${ }^{1}$ Department of Geological Sciences, Arizona State University, Tempe, Arizona, USA.

${ }^{2}$ Department of Astronomy, Space Science Building, Cornell University, Ithaca, New York, USA.

${ }^{3}$ Jet Propulsion Laboratory, California Institute of Technology, Pasadena, California, USA.

${ }^{4}$ Astrogeology Team, U.S. Geological Survey, Flagstaff, Arizona, USA.

${ }^{5}$ Celestial Reasonings, Carson City, Nevada, USA.

interpretations made at the MER sites to other regions of the planet.

[3] The Miniature Thermal Emission Spectrometer (Mini-TES) instruments on board both rovers provide the first opportunity to (1) observe a surface's diurnal temperature variation and acquire Microscopic Imager (MI) and Panoramic Camera (Pancam) imagery of that same surface from close proximity; (2) derive particle sizes from thermal inertia and compare them to grain size distributions measured directly with the MI to validate laboratory conductivity measurements of grain size fractions at Martian atmospheric pressures; (3) test our ability to adequately model the reflection, emission, and absorption into the subsurface of solar and thermal energy and predict the resulting surface temperature; and (4) validate orbital temperature and thermal inertia data. The Mini-TES experiment also provides the potential to better understand nonideal physical properties that can affect modeled temperature results [e.g., Jakosky, 1979].

[4] This work has two primary objectives. The first is to understand the interactions between nonideal surfaces and measured temperatures, which will help determine if Martian surface and subsurface properties are being adequately represented in the current thermal models, and will improve the understanding of orbital data. The second goal is to 
accurately characterize the physical properties of surface materials present at the MER landing sites (e.g., bedforms, particle size distributions, abundance of rock fragments) and explore what these properties imply regarding recent processes that have affected the surface.

\subsection{Instrument Background}

[5] The primary data sets utilized in this study are MiniTES-derived surface temperatures (used to calculate thermal inertia values), the estimated bolometric albedos and images for surface morphology and context derived from the Panoramic Camera (Pancam) [Bell et al., 2003, 2004a, 2004b, 2006] and Microscopic Imager (MI) [Herkenhoff et al., 2003, 2004a, 2004b] images for measuring particle-size distributions. The Mini-TES [Christensen et al., 2003] is a Fourier transform interferometer/spectrometer with spectral range of 339 to $1977 \mathrm{~cm}^{-1}$ (5 to $29 \mu \mathrm{m}$ ). The instrument has two field of view (FOV) options with a spatial resolution of 6.9 and $17.5 \mathrm{mrad}$. The $17.5 \mathrm{mrad}$ FOV was designed for observing targets in the near field, and was utilized most often during the mission.

[6] The Pancam [Bell et al., 2003] is a digital imaging system utilizing two $1024 \times 1024$ pixel frame transfer charge-coupled device (CCD) detector cameras with a $30-\mathrm{cm}$ stereo separation and $0.27 \mathrm{mrad}$ per pixel resolution. Each camera has an eight-position filter wheel (16 filters total, 13 of which are typically used for surface observations), and includes a spectral range of 436$1109 \mathrm{~nm}$.

[7] The MI [Herkenhoff et al., 2003] is mounted on the Instrument Deployment Device (IDD) robotic arm, and is a fixed-focus camera utilizing a $1024 \times 1024$ CCD. This camera acquires images over a spectral range of 400$700 \mathrm{~nm}$ at a spatial resolution of $31 \mu \mathrm{m}$ per pixel at best focus [Herkenhoff et al., 2003]. Single grain sizes can be identified with confidence when they are larger than $\sim 3$ pixels, and this results in the ability to accurately measure grain diameters larger than $100 \mu \mathrm{m}$ [Herkenhoff et al., 2004a].

\subsection{Thermal Inertia Background}

[8] Thermal inertia is controlled by the physical properties of the upper few centimeters of the surface, and is independent of time of day, season, and latitude. It is defined as $I=(\rho k c)^{1 / 2}$, where $\rho$ is the bulk density, $k$ is the thermal conductivity, and $c$ is the specific heat, and is a measure of the resistance of a material to changes in temperature. Units are $\mathrm{J} \mathrm{m}^{-2} \mathrm{~K}^{-1} \mathrm{~s}^{-1 / 2}$ throughout this work (divide by a factor of 41.86 to convert to Viking-era $10^{-3}$ cal cm $\mathrm{cm}^{-2} \mathrm{~K}^{-1} \mathrm{~s}^{-1 / 2}$ units). Under Martian conditions, thermal inertia is primarily a function of the bulk conductivity of the surface because the density and specific heat of geologic materials vary by about a factor of 4 , while thermal conductivity varies by up to 3 orders of magnitude [Wechsler and Glaser, 1965; Neugebauer et al., 1971; Kieffer et al., 1973]. The bulk conductivity is a function of both the solid and gas conductivity, which is largely controlled by particle size and the relationship between pore size and the molecular mean free path of the gas. At Martian pressures the gas molecule mean free path is $\sim 5 \mu \mathrm{m}$. When the pore size is comparable in size or smaller than the gas mean free path (relatively small grains), gas molecules move between grain walls essentially unimpeded by the presence of other gas molecules, resulting in an inefficient transfer of heat. Thus decreasing the particle size increases the number of grain-to-grain contacts per unit length, and decreases both solid and gas conduction [Jakosky, 1986; Presley and Christensen, 1997a]. As a result the thermal inertia is strongly controlled by the effective particle size, which describes the mean particle size of the upper few $\mathrm{cm}$ of surface material if that surface was composed of unconsolidated spheres [Kieffer et al., 1973]. Surfaces dominated by fine-grained material have a lower thermal inertia, and surfaces consisting of rock, duricrust, unconsolidated sand, or any mixture of these materials have a higher thermal inertia. Although thermal inertia does not supply a unique solution to the particle size distribution of surface materials [e.g., Christensen, 1982], it does provide significant insight into the physical nature of the surface and is uniquely related to an effective particle size [Kieffer et al., 1973].

\section{Methods}

[9] Preliminary thermal inertia results at the Spirit and Opportunity landing sites were reported by Christensen et al. [2004a] and Golombek et al. [2005]. Thermal inertia values reported here differ from those initial results due to improvements in the Mini-TES instrument calibration (P. R. Christensen et al., Calibration of a field-deployed infrared spectrometer operating in an extreme, dusty environment: The Mars Exploration Rover Mini-TES, manuscript in preparation, 2006; hereinafter referred to as Christensen et al., manuscript in preparation, 2006), the inclusion of Pancam dust opacity measurements as model input parameters, varying both albedo and thermal inertia to fit diurnal temperature curves, and the use of full diurnal temperature measurements rather than nighttime data only.

\subsection{Modeling Thermal Inertia}

[10] Two techniques were developed in this study to calculate thermal inertia values: (1) fitting a full diurnal curve when diurnal temperature measurements were available or (2) interpolation from a look-up table when a single temperature measurement was used.

\subsubsection{Diurnal Temperature Technique}

[11] To calculate thermal inertia when diurnal temperature measurements were available, we used Mini-TEScalibrated radiance and a thermal model similar to Kieffer et al. [1977]. Model-derived diurnal temperature curves are first calculated using the latitude, season, local time, elevation, and atmospheric dust opacity appropriate for the observation. The latitude, season, and local time are determined from spacecraft ephemeris, and the elevation is derived from a MOLA [Smith et al., 2001] elevation map binned at 8 pixels per degree $(-1.6 \mathrm{~km}$ and $-1.5 \mathrm{~km}$ below datum at Gusev crater and Meridiani Planum, respectively). The dust opacity is determined from Pancam measurements of the visible dust opacity $(\tau)$ taken on the same day [Lemmon et al., 2004].

[12] The Mini-TES data are obtained at multiple times of day to provide good diurnal coverage, and for a minimum of 15 minutes per observation to increase the signal-to-noise ratio. Each spectrum acquired is converted to a surface 
target temperature by fitting a Plank function to the calibrated radiance at each wavelength. The warmest brightness temperature between 500 and $1700 \mathrm{~cm}^{-1}$, selected to avoid wavelength regions where the signal is low, is used to approximate the surface kinetic temperature, and defines the target temperature [Christensen et al., 2004b].

[13] Data obtained at night are important for accurately modeling the thermal inertia because the effects of Sunheated slopes and albedo on surface temperature are minimized, and the thermal contrast due to differences in particle size is at a maximum [e.g., Kieffer et al., 1977; Palluconi and Kieffer, 1981; Christensen, 1982]. The cool nighttime surface does have a lower thermal flux than the daytime surface, which causes the uncertainty in the measured surface temperature to increase. However, the reduced contribution of albedo and slopes on surface temperature at night compensates for this effect, allowing a more reliable derivation of thermal inertia. We define night as between 21 and $6 \mathrm{H}(24 \mathrm{H}$ equals one Martian day and $0 \mathrm{H}$ is local midnight) because the diurnal curves are roughly parallel and linear at this time. Thermal inertias were primarily derived for surfaces with nighttime measurements to ensure the most accurate determination of thermal inertia. The majority of night observations occurred during the primary mission (first 90 sols; sol is defined as the mean length of a Martian day, 24.7 hours [Kieffer et al., 1992]) because the reduction in power as dust settled on the solar panels [Arvidson et al., 2004a, 2004b] made acquiring night measurements more difficult later in the mission.

[14] To determine the thermal inertia, albedo and thermal inertia are varied as model input parameters until a best fit between model-derived diurnal temperature curves and calculated target temperatures of the observed scene are determined using a root-mean square minimization. Some previous thermal inertia data sets, such as TES, used a single-point method to calculate thermal inertia values [Jakosky et al., 2000; Mellon et al., 2000]. The technique used here differs because diurnal temperature measurements are available, and fitting the full diurnal curve is a more accurate method for calculating the thermal inertia. This method is similar to that used with Viking data when diurnal temperature measurements were available [e.g., Palluconi and Kieffer, 1981]. The thermally derived albedo was also compared to Pancam estimated bolometric albedo (here after referred to as Pancam albedo). The Pancam albedo was estimated following the method of Bell et al. [2006] and Reid et al. [1999], where $R^{*}$ is calculated by dividing the $750 \mathrm{~nm}$ filter IOF image by the cosine of the solar incidence angle at the time of the observation and is an approximation of the Lambert albedo within each Pancam band pass [Bell et al., 2006]. The absolute radiance calibration and the relative reflectance of the Pancam instrument (i.e., IOF) are estimated to be within 5-10\% absolute accuracy [Bell et al., 2004a].

[15] The thermal model is a simplified version of a complex system, which is used to predict the surface temperature. In this system, solar and thermal energy from the Sun is filtered through the atmosphere, and some of that energy reaches the surface and is either reflected back into the atmosphere or is conducted into the subsurface; this division is controlled by the surface albedo. Energy is also emitted from the surface, causing some additional energy to reflect off the atmosphere back onto the surface. In addition, emission from objects, such as rocks, in close proximity to the target of interest must also be considered. The thermal model attempts to account for all of these effects, and areas of largest uncertainty include the amount of energy reflected or conducted into the subsurface and the amount of downwelling or backscatter radiance from the atmosphere or nearby objects. By allowing albedo to be a free parameter, we are directly correcting for errors in albedo and indirectly accounting for the downwelling radiance, and the amount of heat energy absorbed by the surface is more accurately estimated [e.g., Palluconi and Kieffer, 1981; Hayashi et al., 1995]. Allowing albedo to be a free parameter, rather than using Pancam albedo values, typically changes the best-fit thermal inertia by less than $10 \%$, but reduces the RMS residuals.

\subsubsection{Single Temperature Technique}

[16] Along the traverse at Gusev and when sampling the rocks at the Colombia Hills, Mini-TES measurements were acquired at a single time of day, requiring a different method for calculating thermal inertias. To determine the thermal inertia with a single measurement, this temperature was interpolated using a seven-dimensional look-up table. To construct this look-up table, surface kinetic temperatures were calculated for a range of albedo, thermal inertia, latitude, local time, season, elevation, and dust opacity values using the same thermal model as the diurnal temperature technique. For the interpolation, latitude, local time, season, elevation, and dust opacity values appropriate for the observation were used. An albedo of 0.22 for the Gusev Plains traverse and 0.15 for rock was assumed for each observation, which corresponds to 0.03 (the average difference between the thermally derived albedo and the Pancam albedo) less than the average Pancam albedo for these surface types.

\subsubsection{Model}

[17] The thermal model used in this study is derived from the Viking Infrared Thermal Mapper (IRTM) thermal model [Kieffer et al., 1977, Appendix 1]; the primary modification has been replacement of a constant atmospheric thermal radiation with a one-layer, radiatively coupled atmosphere of the appropriate thermal capacity. The atmosphere is spectrally gray at solar wavelengths, and direct and diffuse illuminations are computed using a 2 -stream delta-Eddington model. Thermal radiation is assumed to be gray and isotropic, with a fixed ratio of infrared-to-visible opacity. An explicit forward finite difference scheme calculates surface and subsurface temperatures by solving the heat diffusion equation while satisfying a surface boundary condition including direct and diffuse insolation, upward emission and downwelling thermal radiation, and the latent heat of $\mathrm{CO}_{2}$ if its saturation temperature is reached. This model assumes lateral uniformity and a Lambert surface reflection. Subsurface layers increase in thickness exponentially with depth and are scaled to the diurnal skin depth. In this work, the surface emissivity is assumed to be unity and the lower boundary is assumed to be insulating. This model can also incorporate the effects of a radiatively coupled sloped surface at any azimuth. The effects of condensate 
clouds, the latent heat of water ice, and three-dimensional blocks on the surface are not considered.

\subsubsection{Thermal Inertia Derivation Uncertainties}

[18] Different uncertainty determination methods were implemented for each of the two thermal inertia derivation techniques. For diurnal temperature measurements, the thermal inertia errors resulting from model parameter uncertainties were determined using the root-mean square (RMS) residual of the measured temperatures compared to the modeled diurnal temperature curve using the formula RMS $=\left(X^{2}\right)^{1 / 2}$. Errors derived from the RMS are conservative, as the rapid decrease of afternoon temperatures can produce a large difference in temperatures relative to the true quality of the fit. Also thermally derived particles sizes agree with distributions measured directly with MI, further indicating that the reported errors are conservative.

[19] Along the traverse at Gusev, and when sampling the rocks at the Colombia Hills, Mini-TES measurements were acquired at a single time of day, requiring a different method for calculating thermal inertias and assessing their accuracy. The largest sources of error in this technique include the calibration of the instrument (7\%), albedo estimation $(17 \%$, assuming a 0.01 uncertainty), atmospheric dust opacity (9\%, assuming a 0.02 uncertainty), and sloped surfaces. The highest slopes observed along the Gusev traverse were $3^{\circ}$, and can result in uncertainties up to $20 \%$ with an average uncertainty of $10 \%$ during the day. These errors are believed to be uncorrelated, and therefore result in a root sum square (RSS; defined as $\left.\Sigma\left(\mathrm{x}^{2}\right)^{1 / 2}\right)$ error of $12 \%$. This is likely an underestimation, as there are additional uncertainties such as the effect of downwelling radiance and errors in the visible/9- $\mu$ m extinction opacity ratio that are difficult to quantify. However, the thermal inertia derived from MiniTES corresponds well with orbital data, establishing confidence in these results.

[20] The absolute calibration of the Mini-TES instrument determines the accuracy with which the kinetic surface temperature can be approximated, and is a function of both the precision and the accuracy of the instrument. The MiniTES-derived target temperature has a precision and accuracy of $\pm 0.5 \mathrm{~K}$ and $\pm 2 \mathrm{~K}$, respectively for nighttime measurements and $\pm 0.1 \mathrm{~K}$ and $\pm 0.5 \mathrm{~K}$ for daytime measurements for the $17.5 \mathrm{mrad}$ FOV [Christensen et al., 2004b], which corresponds to a $7 \%$ uncertainty in thermal inertia calculations. For further details on the calibration of the Mini-TES instrument, see Christensen et al. (manuscript in preparation, 2006).

[21] The sensitivity of the thermal model to variations in input parameters (e.g., albedo, elevation, and atmospheric dust opacity), and how these sensitivities propagate into thermal inertia uncertainties is important for understanding the sources of error in each observation. These sensitivities were investigated by varying each key parameter while all other parameters were held constant, allowing the determination of the partial derivative of the individual parameter with respect to thermal inertia for each model input. For the diurnal temperature technique used in this study, uncertainties in atmospheric dust opacity and slope measurements are the largest sources of error. An uncertainty in opacity of 0.02 [Lemmon et al., 2004] results in a 9\% error during the day and $0.75 \%$ at night in the resulting thermal inertia. Errors in slope measurements of $3^{\circ}$, and results in an average uncertainty of $10 \%$ during the day and $3.5 \%$ at night.

[22] There are also errors due to uncertainties in the assumed visible/9- $\mu \mathrm{m}$ extinction opacity ratio. A constant ratio of 2.0 was used in this work, but this ratio may vary between $\sim 2.0$ and $\sim 2.5$ for atmospheric dust opacity conditions below 1.0 [Clancy et al., 1995], which includes all of the observations used in this study. Increasing the visible/9- $\mu \mathrm{m}$ extinction opacity ratio increases the modeled temperature at all times of day with a greater effect at night. Varying visible/9- $\mu \mathrm{m}$ extinction opacity ratio from 2.0 to 2.5 changes the modeled temperature $\sim 0.5 \mathrm{~K}$ and $\sim 1.5 \mathrm{~K}$ during the day and night respectively for low opacity conditions $(\tau=0.2)$ and $\sim 1 \mathrm{~K}$ and $\sim 3 \mathrm{~K}$ during the day and night respectively for high opacity conditions $(\tau=0.6)$, producing $10 \%$ uncertainty.

\subsection{Deriving Particle Sizes}

[23] Particle sizes derived from thermal inertia measurements are calculated using the technique described by Presley and Christensen [1997a]. From laboratory measurements under Martian conditions, Presley and Christensen [1997a] determined a linear relationship between the log of the thermal conductivity and the log of the particle diameter and derived parameters that relate conductivity to particle size using the following equation:

$$
\mathrm{k}=\left(\mathrm{CP}^{0.6}\right) \mathrm{d}^{-0.11 \log (\mathrm{P} / \mathrm{K})},
$$

where $C$ and $K$ are the constants 0.0015 and $8.1 \times 10^{4}$ torr (to convert to Pascal units, multiply 1 torr by $133.3 \mathrm{~Pa}$ ), respectively [Presley and Christensen, 1997a], $P$ is atmospheric pressure in torr, and $d$ is the particle diameter in $\mu \mathrm{m}$. This equation can be substituted into the definition of thermal inertia to obtain an equation that relates particle size to thermal inertia:

$$
\mathrm{d}=\left(\mathrm{I}^{2} / \rho \mathrm{cCP} \mathrm{P}^{0.6}\right)^{1 /-0.11 * \log (\mathrm{P} / \mathrm{K})},
$$

where $\rho c$ is assumed to be $1 \times 10^{6} \mathrm{~J} \mathrm{~m}^{-3} \mathrm{~K}$ [Neugebauer et al., 1971]. This equation was used to derive an effective particle size [Kieffer et al., 1973] from thermal inertia assuming an atmospheric pressure of 600 Pascals (Mars surface pressure at $-1.5 \mathrm{~km}$ and $\mathrm{L}_{\mathrm{s}}=0^{\circ}$ [Smith and Zuber, 1998]). Equation (1) is valid for thermal inertias less than $\sim 350$. Thermal inertias larger than this value are more difficult to interpret, but this relationship provides a reasonable estimate. Errors in deriving particle sizes with this method are expected to be less than 10-15\% [Presley and Christensen, 1997a]. These thermally derived particle sizes are compared to particle sizes measured directly in MI images, where available, to validate the accuracy of this technique.

[24] There are several caveats to calculating particle sizes from thermophysical properties. This technique requires that the surface consists of unconsolidated sediments down to at least a diurnal thermal skin depth [e.g., Jakosky, 1986], and that particles are loosely packed and of a single, spherical grain size. Packing of grains, mixtures of particles where pore spaces between larger grains are filled by smaller ones, and nonspherical grains typically increase 
Table 1. Thermal Inertia, Uncertainties, Thermally Derived Albedo, and Pancam Estimated Bolometric Albedo for Each Mini-TES Diurnal Observation

\begin{tabular}{|c|c|c|c|c|c|}
\hline & Thermal Inertia & Temperature RMS & $\Delta$ Inertia RSS & Thermally Derived Albedo & $\begin{array}{l}\text { Pancam Estimated } \\
\text { Bolometric Albedo }\end{array}$ \\
\hline \multicolumn{6}{|c|}{ Gusev } \\
\hline Middle Ground & 150 & 1.950 & $28(18.7 \%)$ & 0.18 & 0.27 \\
\hline Bonneville Upper Dunes & 200 & 2.467 & $40(20 \%)$ & 0.16 & 0.18 \\
\hline Bonneville Lower Dunes & 160 & 2.286 & $35(21.9 \%)$ & 0.16 & 0.23 \\
\hline Saber & 250 & 2.896 & $42(16.8 \%)$ & 0.27 & 0.29 \\
\hline Beacon & 1200 & 1.707 & $295(21.1 \%)$ & 0.11 & 0.18 \\
\hline \multicolumn{6}{|c|}{ Meridiani } \\
\hline \multirow[t]{2}{*}{ Plains } & 100 & 6.340 & $71(71 \%)$ & 0.12 & 0.12 \\
\hline & 150 & 5.912 & $72(48 \%)$ & & \\
\hline Endurance Dunes & 200 & 2.037 & $28(14 \%)$ & 0.09 & 0.12 \\
\hline Endurance Sand & 100 & 1.589 & $23(23 \%)$ & 0.14 & 0.13 \\
\hline
\end{tabular}

the conductivity [Fountain and West, 1970; Wechsler et al., 1972; Presley and Christensen, 1997b]. Many of these conditions occur in natural surfaces, and future laboratory measurements addressing heat conduction in crusts, particle size mixtures, and nonspherical grains are needed in order to extend thermal inertia observations from simple unimodal granular material to more complex surfaces.

\section{Results and Discussion}

[25] The results of this study are separated into two sections: (1) thermal modeling results of major Martian surface types identified from orbit, which are dust, sand, and rock, and (2) specific examples from both Gusev crater and Meridiani Planum. A summary of thermal inertias, uncertainties, thermally derived albedo values, and Pancam albedo values are provided in Table 1. Because the accuracy of the thermal inertia calculation differs for day and night measurements, the RSS (defined as $\left.\Sigma\left(\mathrm{x}^{2} / \mathrm{n}\right)^{1 / 2}\right)$ of uncertainty for each observation is reported.

\subsection{Surface Types}

\subsubsection{Dust}

[26] Some of the finest-grained material observed at the MER landing sites is located in shallow sediment-filled depressions in Gusev crater. These features, named hollows, are interpreted as having been formed by impacts and filled with aeolian material [Grant et al., 2004; Golombek et al., 2006]. One example is Middle Ground (Figure 1a), which is roughly equidistant from the landing site named Columbia Memorial Station (CMS) [Squyres et al., 2004a] and Bonneville crater, and was observed on MER-A sols 55-57. The modeled thermal inertia of this material is 150 (Figure 1b), which implies $\sim 45 \mu \mathrm{m}$ diameter particles (silt). The thermally derived albedo is 0.18 , and the Pancam albedo is 0.27. A similar hollow, Laguna ( $\sim 40 \mathrm{~m}$ from Middle Ground), was trenched with the rover wheel to expose cohesive material to a depth of 6-7 cm [Squyres et al., 2004a]. MI images of the Laguna trench indicate that grains are sometimes clumped together, but individual particles are too small to measure with the MI instrument (less than $100 \mu \mathrm{m}$ ) (Figure 2). This observation is consistent with the thermal inertia values and particle sizes derived from Mini-TES.

[27] The particle sizes, both implied by the thermal inertia and measured using MI images, are higher than the diameter of dust particles suspended in the atmosphere $(\sim 2.5 \mu \mathrm{m}$ [Pollack et al., 1979; Toon et al., 1977]), and the Mini-TES emissivity spectra of the Laguna trench material contains features that are consistent with basaltic material [Wang et

(a)
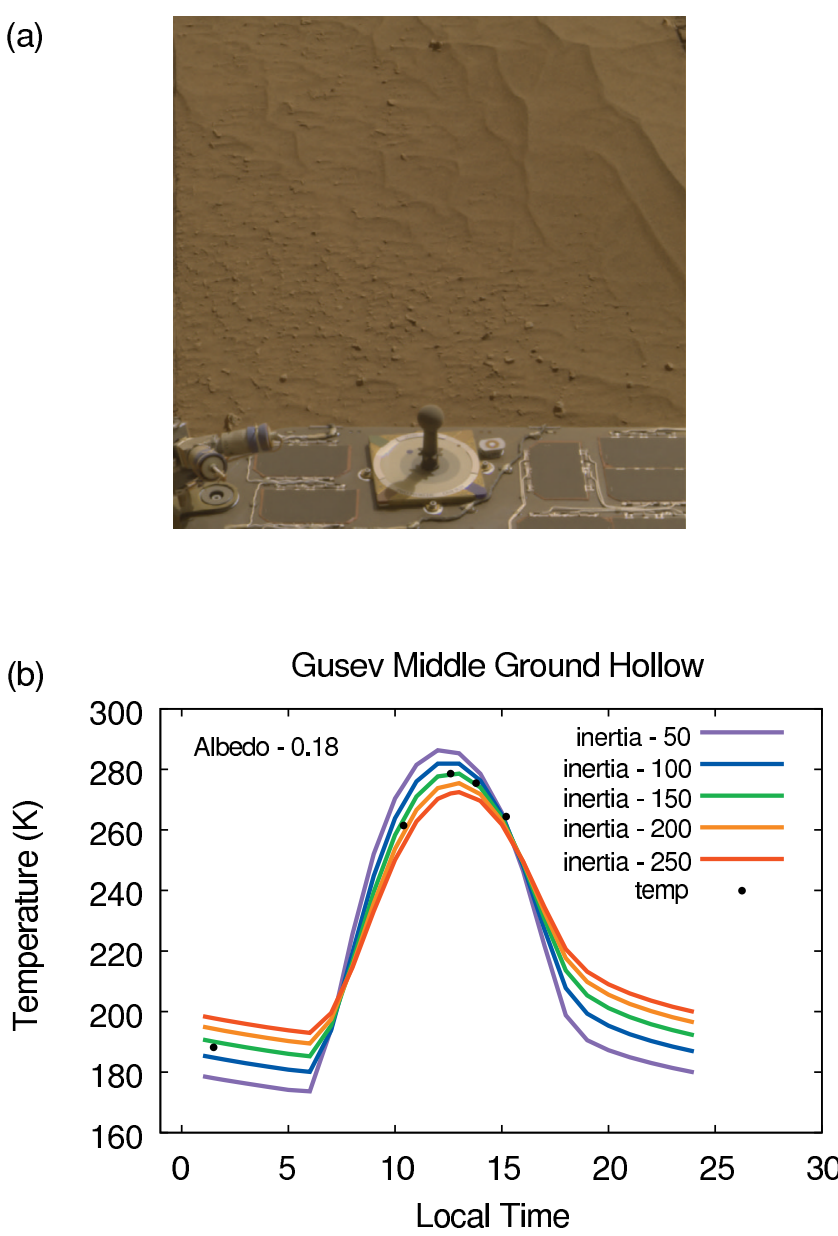

Figure 1. Gusev crater hollow. (a) Middle Ground Hollow (Pancam approximate true color image 2P131347008FFL1155P2584, sol 056). For scale, the Pancam calibration target in the lower center of the image is $20 \mathrm{~cm}$. (b) Plot of the modeled diurnal temperature curve (using an opacity of 0.76 and Ls of $357.5^{\circ}$ ) and Mini-TES target temperatures; RMS error is $2.0 \mathrm{~K}$. 


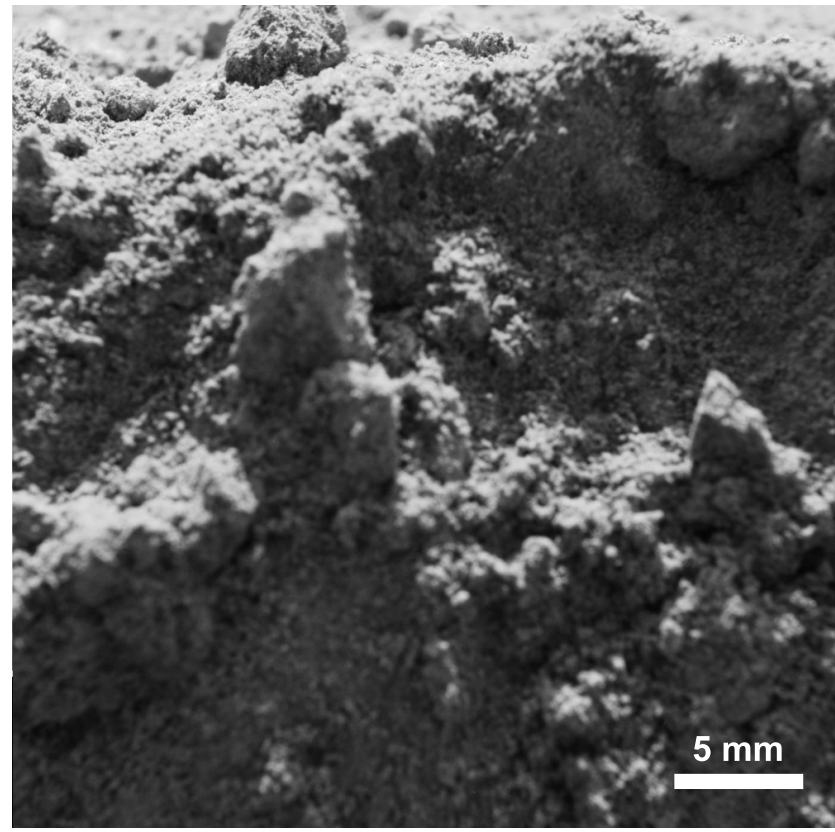

Figure 2. Subsurface of Gusev crater hollow. MI image 2M130618323FFL09BVP2955 (sol 048) of the subsurface of Laguna Hollow. The inability to obtain a focused image suggests particles below the instrument resolution (less than $100 \mu \mathrm{m})$. al., 2006] greater than $\sim 60 \mu \mathrm{m}$ [e.g., Ruff and Christensen, 2002]. Thus it is unlikely that the material inside the hollows originated from airfall dust alone, and it is instead probable that aeolian transportation of fine material from the plains and the deposition of airfall dust is filling these hollows simultaneously. There are also few rock fragments inside the hollows, in contrast to the surrounding plains, and their absence is potentially the cause for the reduced thermal inertia in the hollows, relative to the surrounding region. These observations support the hypothesis of Grant et al. [2004] who proposed that regionally derived fines, possibly resulting from impacts, have filled the hollows on the Gusev plains.

\subsubsection{Sand}

[28] The bedforms on the floor of Endurance crater at Meridiani Planum was observed on MER-B sols 211-215 (Figure 3). These bedforms have sharp crests and a Pancam albedo $\sim 0.12$, suggesting a relatively dust-free surface. The bedform crests have many different orientations, providing evidence for a complicated wind regime that is likely due to the crater topography. These bedforms have an overall net zero slope, but the viewing geometry restricted Mini-TES to observe primarily west-facing slopes and some interbedform material. This morphology was approximated in the determination of thermal inertia by incorporating equal components of a horizontal surface and a west-facing slope at an angle of $15^{\circ}$, causing the bedform to receive more heat in the afternoon (Figure 4a).

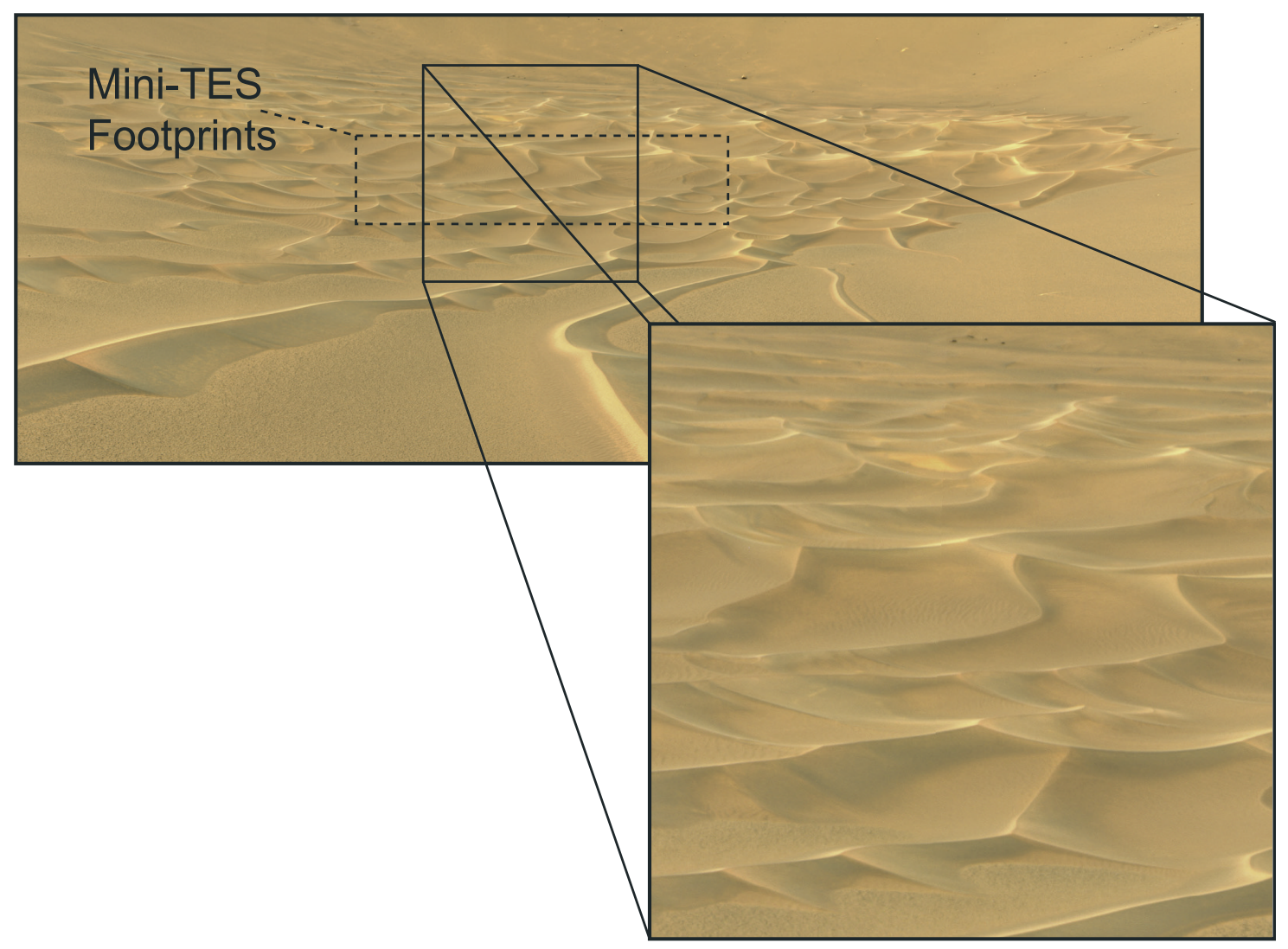

Figure 3. Meridiani Planum Endurance crater bedforms. Pancam approximate true color mosaic of Endurance bedforms, including the approximate location of the Mini-TES observations. 
(a)

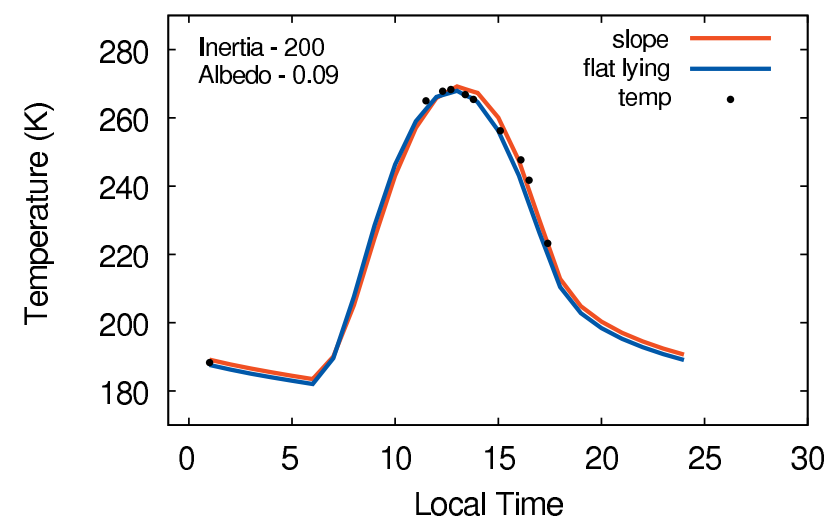

(b)

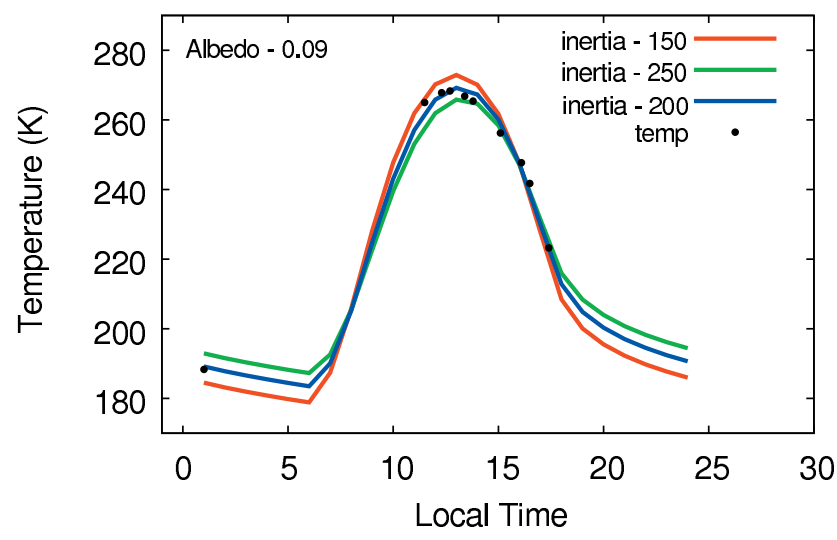

Figure 4. Diurnal temperature curve of Meridiani Planum Endurance crater bedforms. (a) Plot of the modeled diurnal temperature curve for a flat-lying surface (RMS error is $3.3 \mathrm{~K}$ ) and a sloped surface (RMS error is $2.0 \mathrm{~K}$ ) approximating the morphology of Endurance bedforms, and Mini-TES target temperatures. (b) Plot of the modeled diurnal temperature curve (using an opacity of 0.50 and Ls of $80^{\circ}$ ) and Mini-TES target temperatures; RMS error is $2.0 \mathrm{~K}$.

The average modeled thermal inertia of the entire bedform is 200 (Figure $4 \mathrm{~b}$ ), corresponding to a particle diameter of $160 \mu \mathrm{m}$ (fine sand), and the thermally derived albedo is 0.09 . The rover did not traverse to these bedforms because the area surrounding the bedforms was untrafficable, and thus an MI measurement of the same surface observed by the Mini-TES was not acquired. However, an MI image of a patch of sand near the wall of the crater that is presumably the same material as the bedforms was acquired. The average measured particle size of this bedform was $\sim 130 \mu \mathrm{m}$, which corresponds well with the particle diameter derived from the Mini-TES thermal inertia value.

3.1.3. Rock

[29] The rock informally named Bonneville Beacon at Gusev crater (Figure 5) was observed on MER-A sol 47 during the day only. The rover was also trenching in Laguna Hollow during this time, and power constraints for these operations were significant. This rock is darker (Pancam albedo of 0.18 ) than rocks typically observed on the plains, suggesting a lack of coating or dust mantle. Bonneville Beacon is $\sim 75 \mathrm{~cm}$ in length and is larger than the diurnal skin depth of solid rock ( $\sim 15 \mathrm{~cm}$ [Christensen, 1986]); no temperature gradient along the rock was observed. Since Mini-TES is observing the outside surface of the rock and Bonneville Beacon is only $\sim 5$ thermal skin depths in length, boundary effects may be causing the warmer rock surface thermal inertia to be lower than that of the rock interior because warmer temperatures are consistent with lower thermal inertias during the day. The slope and azimuth angles of the rock faces viewed by Mini-TES were estimated using Pancam imagery. Diurnal temperature curves modeled for a slope angle of $60^{\circ}$ at azimuth angles of $45^{\circ}$ and $160^{\circ}$ were added in equal proportions to best represent the orientation of the rock target causing mid-day and afternoon temperatures to be modeled $\sim 10^{\circ} \mathrm{K}$ and $\sim 3^{\circ} \mathrm{K}$ lower, respectively, than a horizontal surface (Figure 6a). Incorporating these slopes has an effect similar to that of increasing the thermal inertia, and therefore this thermal inertia estimate is likely a lower limit. The modeled thermal inertia after accounting for slopes is 1200 (Figure 6b), and the thermally derived albedo is 0.11 . The thermal inertia of a basalt rock is expected to be $\sim 2200$ (assuming $\rho=2800 \mathrm{~kg} \mathrm{~m}^{-3}, \mathrm{k}=$ $2.1 \mathrm{~J} \mathrm{~s}^{-1} \mathrm{~m}^{-1} \mathrm{~K}^{-1}, \mathrm{c}=840 \mathrm{~J} \mathrm{~K}^{-1} \mathrm{~kg}^{-1}$ [Kahle, 1980]), which corresponds to a temperature difference of $2.5 \mathrm{~K}$ during the day and $4.5 \mathrm{~K}$ at night between these two thermal inertia values. The thermal inertia is that expected for a basaltic rock this size, and given the uncertainties in measuring surface temperature, is comparable to that of an infinite slab of basalt. The lower modeled thermal inertia may potentially be due to weathering, the presence of a dust coating, micro-fractures within the rock [Robertson and Peck, 1974; Zimbelman, 1986], or the Mini-TES footprints being closer than $15 \mathrm{~cm}$ from the rock edge causing warmer temperatures to be observed.

\subsection{Surface Properties at the MER Landing Sites}

\subsubsection{Spirit Landing Site in Gusev Crater}

\subsubsection{Gusev Plains Soil}

[30] At Gusev, a campaign was implemented to systematically monitor properties of the soil (following the convention of previous authors [e.g., Squyres et al., 2004a], soil is used here to denote any loose, unconsolidated materials that can be distinguished from rocks, bedrock, or strongly cohesive sediments; no implication of the presence or absence of organic materials or living matter is intended) along the traverse from Columbia Memorial Station (CMS) to Bonneville crater and the Columbia Hills. This included, among other observations, measurements of the surface radiance with Mini-TES to model thermal inertia and acquisition of Pancam imagery of the same surface for context. From Pancam imagery, these surfaces are composed of a combination of fines, pebbles, cm-sized rock fragments, and rocks (Figure 7). The results of this survey (Figure 8) indicate a consistently low thermal inertia (avg. $\sim 175 \pm 20$, corresponding to particles of $\sim 90 \mu \mathrm{m}$, silt) from the CMS (Figure 7a) to the Bonneville crater ejecta, where the thermal inertia values increase sharply. The observed increase in cm-sized rock fragments and higher rock abundance in the ejecta [Golombek et al., 2005, 2006] suggests that this sharp increase in thermal inertia 


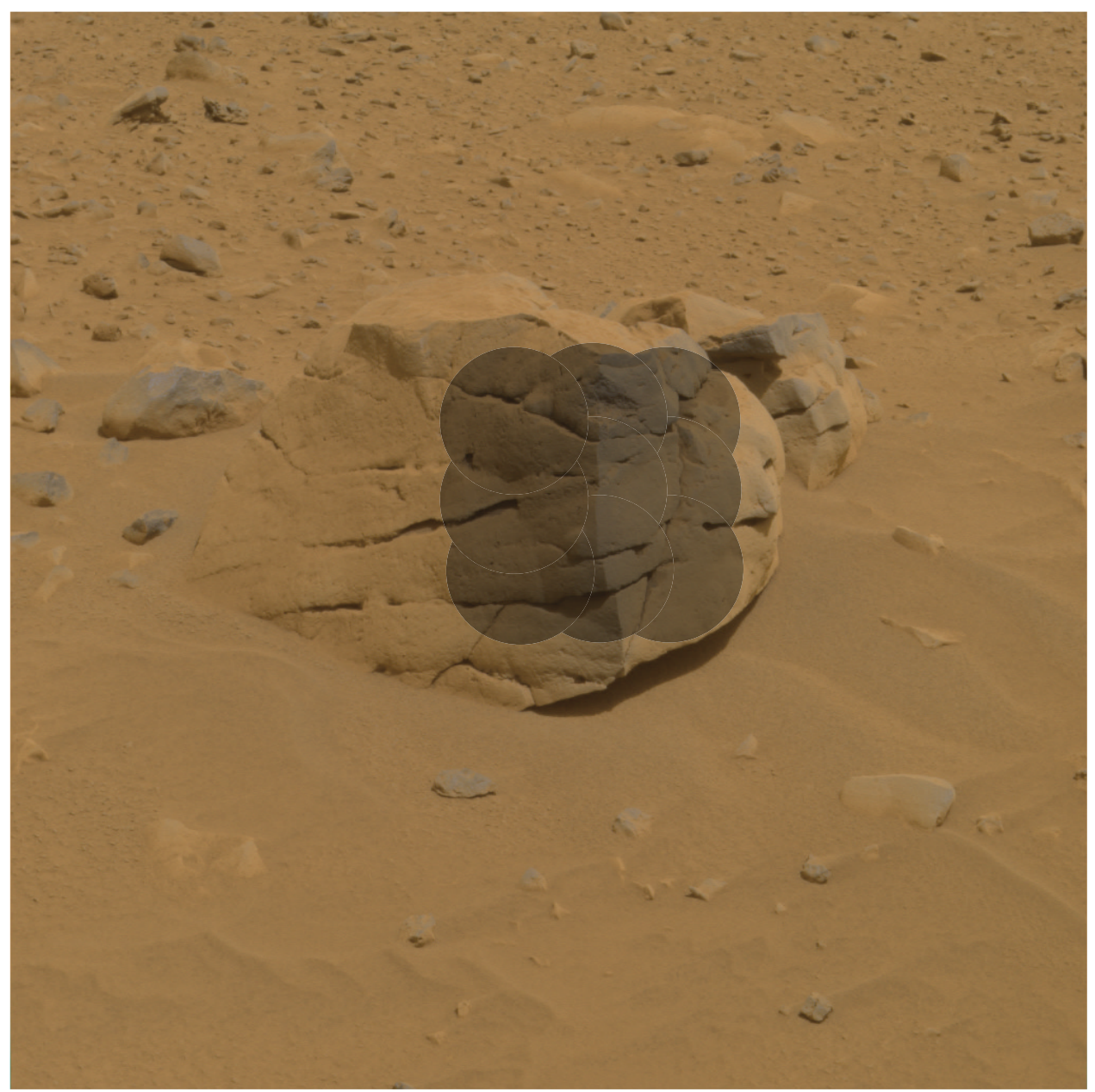

Figure 5. Gusev crater rock Bonneville Beacon. Pancam approximate true color image (2P130443835FFL0900P2555, sol 046) of the rock target Bonneville Beacon and the approximate locations of the Mini-TES footprints that were used in this analysis. Bonneville Beacon is $\sim 0.75 \mathrm{~m}$ in length.

does not indicate a change in soil properties, but instead reflects the increased number or size of clasts or rock in the Mini-TES FOV. From Bonneville crater to the Columbia Hills, the thermal inertia of the soil is higher (avg. $\sim 250 \pm 30$ ) than from CMS to Bonneville crater, and there is more variability in the thermal inertia measurements. The greater variability is likely caused by changes in the amount of rock fragments and aeolian drift material in this area. The traverse from Bonneville crater to the Columbia Hills also has an overall higher thermal inertia. This increase is probably due to the presence of more rock fragments as observed in Pancam images (Figures 7b, 7c, and $7 \mathrm{~d})$.

[31] For scenes containing rock fragments and when nighttime temperature observations were acquired, the thermal inertia of the soil alone was computed by removing the effects of the fragments. The average length of rock fragments in the Mini-TES FOV was measured using Pancam imagery, and two techniques were used to estimate their thermal inertia. The rock fragment thermal inertia was estimated using equation (1) [Presley and Christensen, 1997a], and because these rock fragments have a thermal inertia greater than 350 , the resulting uncertainties may be larger than 10-15\% [Presley and Christensen, 1997a]. However, the range of thermal inertia values for rock fragments (540 to 820 ) is a reasonable estimate, assuming that the relationship between conductivity and particle size established using laboratory data and extrapolated to rock follows a smooth curve [Kieffer et al., 1973]. Jakosky [1986] argued that particle diameters of $1 \mathrm{~mm}$ to $<$ a few $\mathrm{cm}$ have a constant thermal inertia of $\sim 420$. Since the measured rock fragments ranged in size from 1.5 to $4 \mathrm{~cm}$ this constant value was assumed to be the thermal inertia for all rock fragments. From this thermal inertia, a temperature and then a surface radiance of the rock component was derived. The percentage of rock in the Mini-TES FOV was estimated from Pancam imagery, and this percentage of calculated rock radiance was subtracted from the measured radiance of Mini-TES to obtain the radiance of the entire target minus the radiance contribution from the rocks using the following relationship:

$$
\mathrm{R}_{\mathrm{m}}=\alpha_{\mathrm{s}} * \mathrm{R}_{\mathrm{s}}+\left(1-\alpha_{\mathrm{s}}\right) * \mathrm{R}_{\mathrm{r}},
$$

where $R_{m}$ is the measured radiance with Mini-TES, $\alpha_{s}$ is the percentage of soil in the Mini-TES FOV, $\mathrm{R}_{\mathrm{s}}$ is the radiance 
(a)

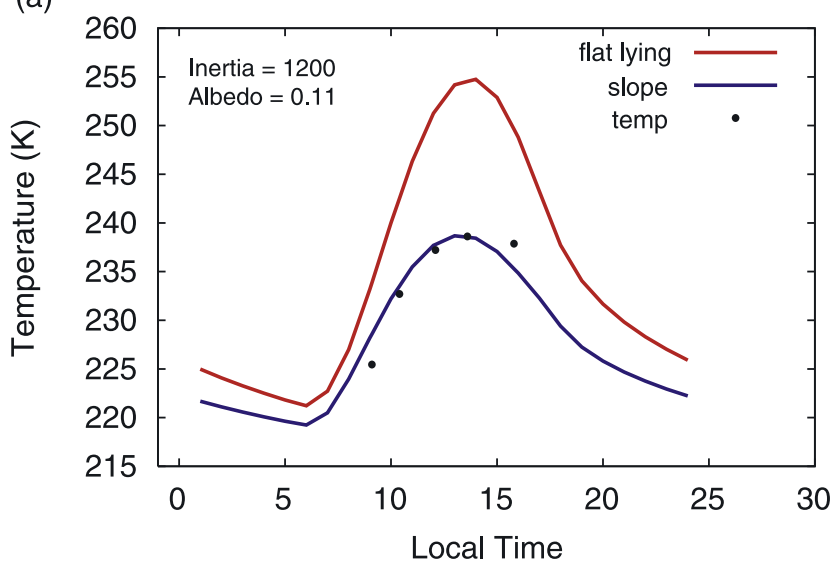

(b)

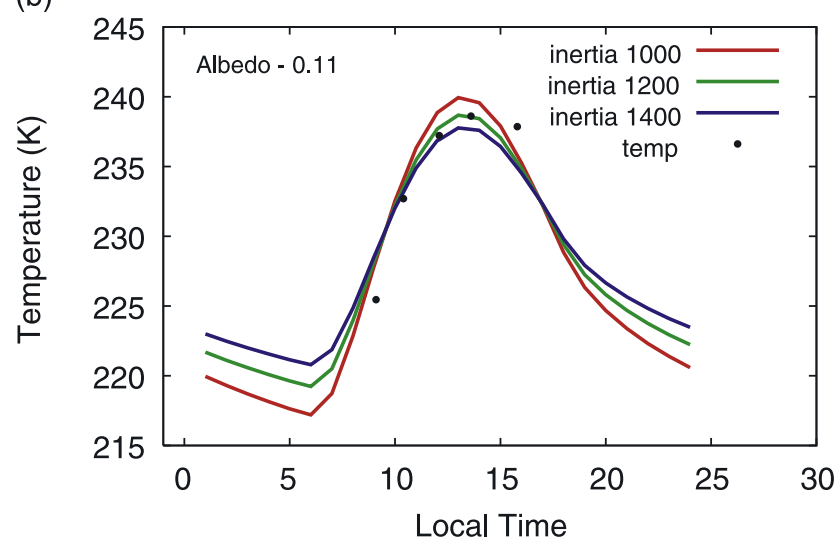

Figure 6. Diurnal temperature curve of Gusev crater rock Bonneville Beacon. (a) Plot of the modeled diurnal temperature curve for a flat-lying surface (RMS error is $12.0 \mathrm{~K}$ ) and a sloped surface (RMS error is $1.7 \mathrm{~K}$ ) approximating the geometry of the rock Bonneville Beacon, and Mini-TES target temperatures. (b) Plot of the modeled diurnal temperature curve (using an opacity of 0.76 and Ls of $352.7^{\circ}$ ) and Mini-TES target temperatures; RMS error is $1.7 \mathrm{~K}$.

of the soil, and $\mathrm{R}_{\mathrm{r}}$ is the estimated radiance of the rock component. This soil radiance is converted to a brightness temperature, then a derived thermal inertia, to obtain an estimate of the thermal inertia of the soil. Errors in this technique are primarily due to inaccuracies in measuring the length of rock fragments $(<5 \%)$, estimating the percentage of rock in the Mini-TES FOV $(<5 \%)$, uncertainties in calculating the thermal inertia (12\%), and uncertainties in the Mini-TES instrument calibration (7\%). Thermal inertia estimates for the minimum, maximum, and average size rock fragments at each location using equation (2) differed by less than $10 \%$, and using a rock fragment thermal inertia of 420 [Jakosky, 1986], rather than 540 to 820 , produced a thermal inertia of the soil $\sim 10$ units lower. The estimated thermal inertia of the soil at the measured locations is $\sim 200 \pm 20$, corresponding to a particle diameter of $\sim 160 \mu \mathrm{m}$ (fine sand). The thermal inertia of the soil was measured at MER-A sol 45 and sol 65 ( 200 $\mathrm{m}$ apart), and both measurements were within 50 units of one another. This result suggests that the soil properties do not change significantly along the traverse from CMS to Bonneville crater and that the increase in observed thermal inertia from orbit is due to additional rock abundance as the rover approached the crater ejecta material, in agreement with earlier results [Christensen et al., 2004a; Golombek et al., 2005, 2006; Moersch et al., 2005].

\subsubsection{Aeolian Bedforms}

[32] The most prominent bedform observed at the Gusev site is located in Bonneville crater (Figure 9). This aeolian material is prevalent on the crater floor and part of the south-facing wall. Rocks were observed poking through this aeolian sediment suggesting that this deposit is less than a meter or two thick [Grant et al., 2004]. Since the diurnal skin depth of medium sand is $\sim 7.5 \mathrm{~cm}$ [Edgett and Christensen, 1991] and there are no rocks observed within the Mini-TES FOV, the measured temperatures are likely determined by the bedform material and are not influenced by any potential coarser material on the crater floor. Two sections of this bedform were modeled: (1) an upper section that climbs the north crater wall (modeled slope of $11^{\circ}$ [Grant et al., 2004]) and has a lower Pancam albedo $(\sim 0.18)$ and (2) a lower portion that occurs on the crater floor and has a higher Pancam albedo $(\sim 0.23)$. The modeled thermal inertia for the upper bedform section is 200 (Figure 10a), which corresponds to a particle diameter of $\sim 160 \mu \mathrm{m}$ (fine sand). The lower bedform section has a thermal inertia of 160 (Figure 10b), suggesting $\sim 60 \mu \mathrm{m}$ diameter particles (silt). Both areas have a thermally derived albedo of 0.16 . The aeolian sediment on the crater floor and wall may be of the same origin, and a layer $(\leq 1 \mathrm{~cm})$ of dust may be causing the increased Pancam albedo and lower thermal inertia on the crater floor. The coarser, darker grains of the upper bedform section are consistent with bedforms that have been active more recently than the lower bedform section because they presumably have less dust mantling their surface.

[33] The Saber and Serpent targets are aeolian bedforms near the rim of Bonneville crater. The rover disturbed Serpent using its wheel, which revealed an outer armor of coarser grains that may be a lag deposit of windblown material that has been transported in traction by the impact of smaller saltating grains [Greeley et al., 2004]. In addition, the interior material was composed of dust well mixed with sand, indicating that the sand grains are not currently saltating [Greeley et al., 2006]. It is likely that the Saber bedform has an armor and interior similar to Serpent because of the similar albedo, temperature, morphology, and proximity of these bedforms. The thermal inertia of the undisturbed Saber bedform is 250, corresponding to a particle diameter of $\sim 415 \mu \mathrm{m}$ (medium sand). This bedform has a thermally derived albedo of 0.27 and a Pancam albedo of 0.29 . These results correspond to MI images of the disturbed Serpent bedform (Figure 11a), indicating a trimodal distribution of particle sizes of 1-2 mm, 250-500 $\mu \mathrm{m}$ and below $210 \mu \mathrm{m}$ [Herkenhoff et al., 2004a]. A layer of 1-2 mm particles does not significantly affect the thermal inertia of this bedform. Although the 1-2 $\mathrm{mm}$ armor does increase the thermal inertia, in this layered case the surface temperature is dominated by the fine-grained substrate (Figure 11b). 

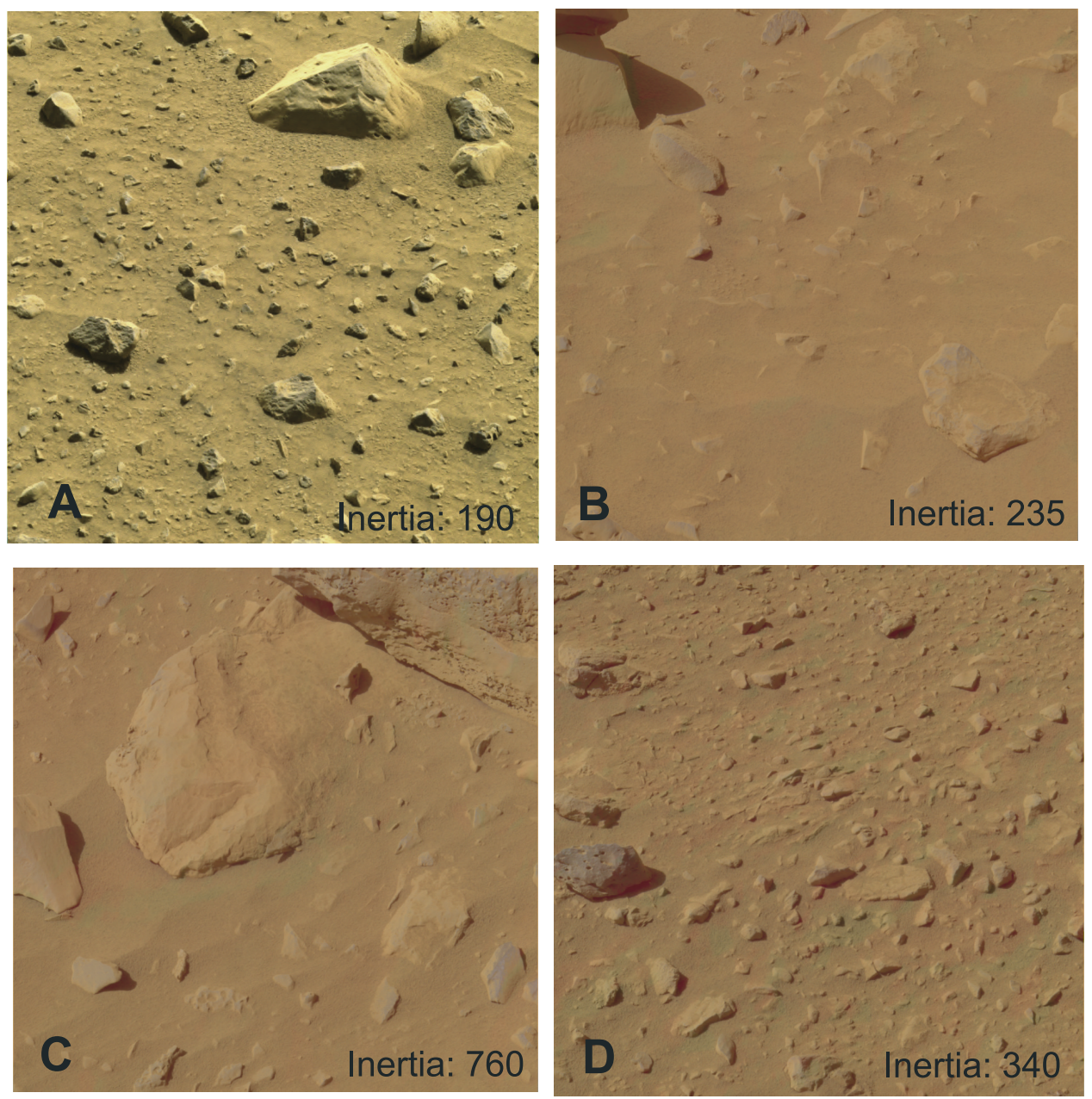

Figure 7. Type examples of Gusev plain surfaces. Pancam approximate true color images along the traverse: (a) 2P130264291FFL0700P2540 (site 7, sol 044), (b) 2P136034758FFL3300P2460 (site 33, sol 109), (c) 2P239052324FFL5500P2460 (site 55, sol 143), and (d) 2P143136938FFL7100P2460 (site 71, sol 189).

The armor is a small percentage of the total bedform, and thus the thermal energy is conducted rapidly through the 1-2 $\mathrm{mm}$ layer, but is then impeded by the smaller particles. This result also implies that there are few 1-2 $\mathrm{mm}$ grain particles below the armor, as these grains would dominate the observed bedform thermal inertia [Presley and Christensen, 1997b]. Thus the thermally derived particle size $(\sim 415 \mu \mathrm{m})$ is consistent with MI observations.

\subsubsection{Rock and In-Place Bedrock}

[34] The rock informally named Bonneville Beacon at Gusev crater has a modeled thermal inertia of $\sim 1200$, and a thermally derived albedo of 0.11 (Figures 5 and 6). The thermal inertia is that expected for a basaltic rock this size, as the thermal inertia of a solid, dense, infinite slab of basaltic rock is $\sim 2200$, and would have a temperature within $2.5 \mathrm{~K}$ during the day and $4.5 \mathrm{~K}$ at night of the temperature at Bonneville Beacon. This lower thermal inertia may be due to Mini-TES observing a warmer rock surface relative to the cooler interior, or from physical characteristics such as weathering, the presence of a dust coating, or micro-fracturing [Robertson and Peck, 1974; Zimbelman, 1986] within the rock. This comparison suggests that Bonneville Beacon is nonvesicular igneous material, rather than a sedimentary or volcaniclasic rock, and may be a portion of a basaltic lava flow that has been exhumed from the subsurface by impact events.

[35] Rocks at the lower Columbia Hills have a different chemical composition and physical appearance than rocks observed on the plains [Arvidson et al., 2006], but a highquality diurnal temperature curve has not yet been acquired in the Columbia Hills. So to assess the thermal inertia of rocks in this region, 11 rock targets with single Mini-TES measurements were chosen on the basis of the following criteria: (1) the Mini-TES footprint was located completely on the rock, (2) the rock size was more than $15 \mathrm{~cm}$ in diameter (diurnal skin depth of rock [Christensen, 1986]), (3) no rover shadow was present, and (4) the observation was taken before $14 \mathrm{H}$ because at later times of day the diurnal curves converge resulting in all thermal inertia values having similar temperatures. The average thermal inertia of any rock selected was $\sim 620$ (maximum was $1100 \pm 130$ ). This average thermal inertia value is lower than the Bonneville Beacon thermal inertia on the Gusev Plains (1200) resulting in an $5 \mathrm{~K}$ temperature difference during the day. This variation suggests that thermal inertia 
THEMIS and Mini-TES Thermal Inertia

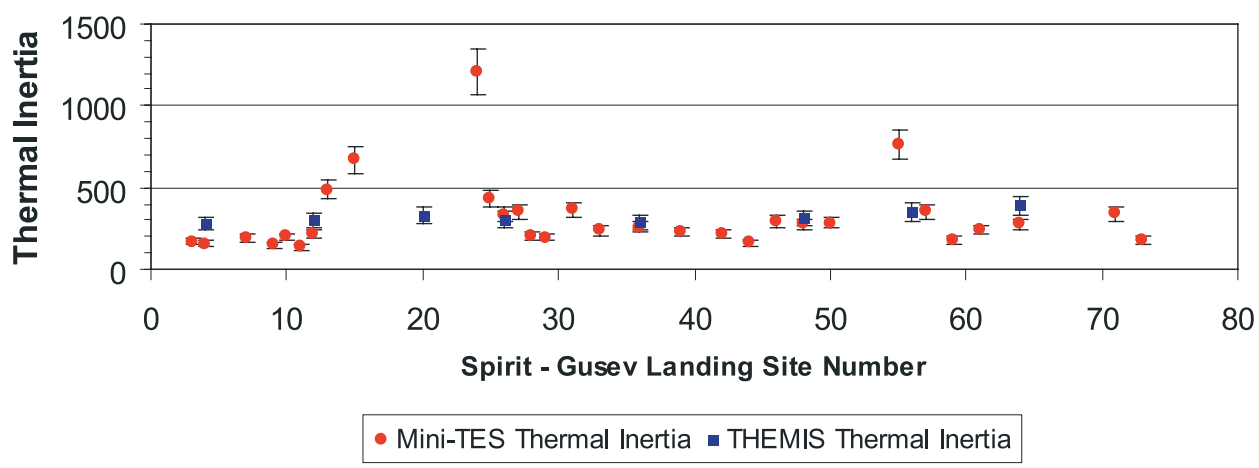

Figure 8. Comparison of Mini-TES-derived surface and THEMIS-derived orbital thermal inertia values. Plot comparing the thermal inertia trends between THEMIS-derived thermal inertia from orbit and Mini-TES-derived thermal inertia of the surface.

can discriminate real differences in the density or porosity of rocks at different locations, and differentiate between dense and friable, weathered rocks. On the basis of the amount of energy necessary to grind rocks using the Rock Abrasion Tool (RAT), the rocks at the lower Columbia Hills are easier to grind (average energy per volume of rock removed of $15 \mathrm{~J} / \mathrm{mm}^{3}$ ) than rocks on the Gusev plains (average energy per volume of $52 \mathrm{~J} / \mathrm{mm}^{3}$ ) (S. Gorevan et al., Analytical developments and results for rock specific grind energy from the Mars Exploration Rover Rock Abrasion Tool, manuscript in preparation, 2006; hereinafter referred to as Gorevan et al., manuscript in preparation, 2006). Since the energy required relates directly to rock density, among other properties, these results corrob- orate the thermal inertia differences. A possible interpretation is that the Gusev plains primarily consist of dense basaltic rock, whereas the lower Columbia Hills is consistent with friable volcaniclastic ash or impact debris [Arvidson et al., 2006].

\subsubsection{Opportunity Landing Site in Meridiani Planum}

\subsubsection{Meridiani Plains Soil}

[36] The surface at Meridiani Planum is dominated by low ripples $(\sim 1 \mathrm{~cm})$ spaced an average of $10 \mathrm{~m}$ apart, and is covered with $0.6-6 \mathrm{~mm}$ diameter hematite spherules [Herkenhoff et al., 2004b], and a set of aeolian bedforms interpreted as wind ripples [Squyres et al., 2004b; Bell et al., 2004b; Soderblom et al., 2004; Sullivan et al., 2005]. The spherules are relatively free of adhering dust

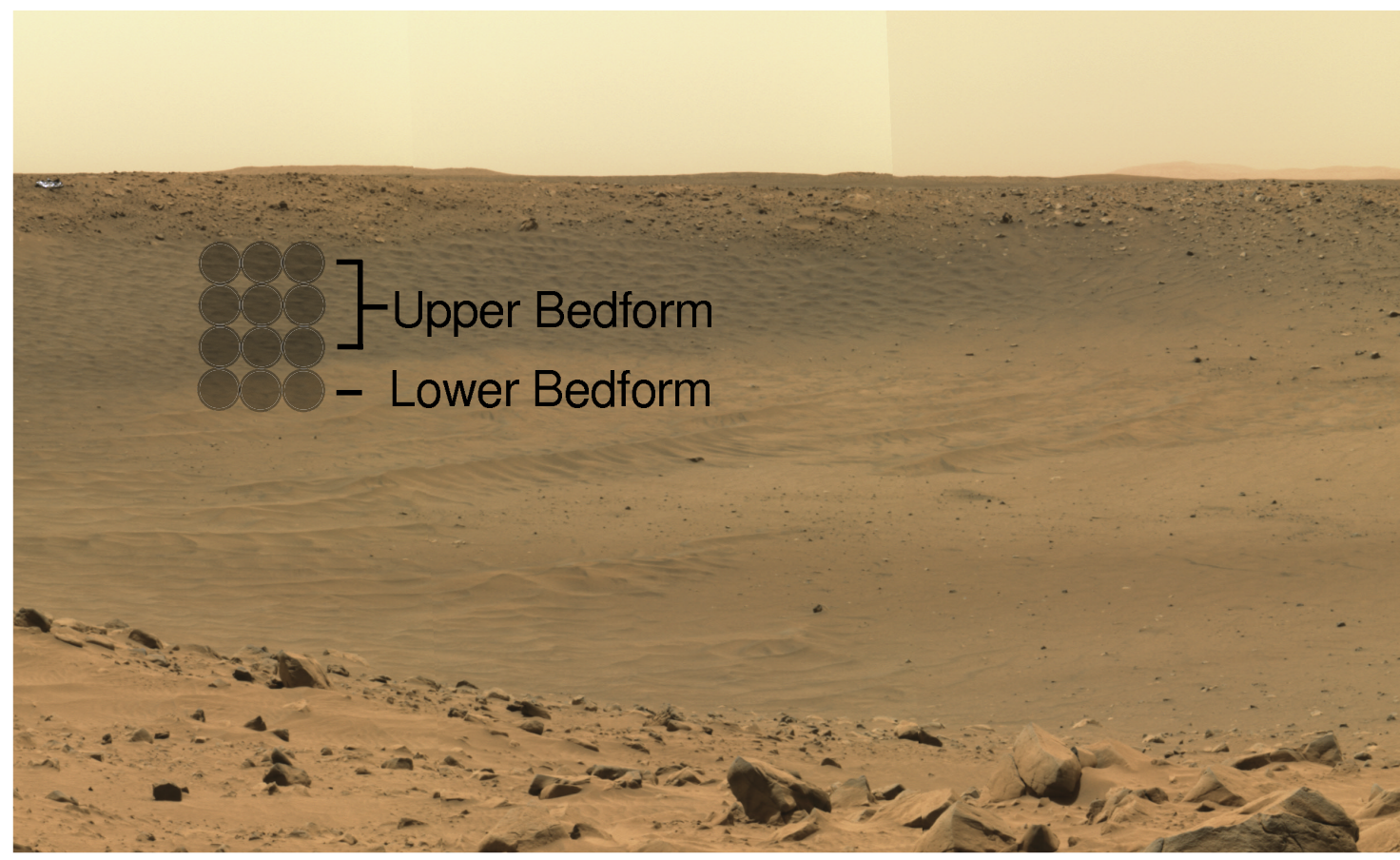

Figure 9. Bedforms in Bonneville crater. The intracrater bedforms in Bonneville crater (Pancam approximate true color image 2P132398796FFL1800P2285, sol 068) and the locations of the Mini-TES footprints that were used in this analysis. For scale, Bonneville crater diameter is $\sim 210 \mathrm{~m}$. 
(a)

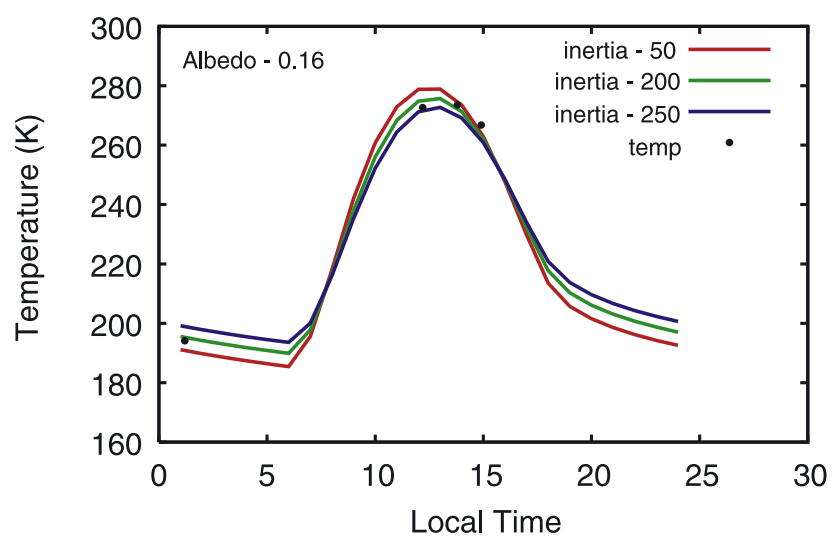

(b)

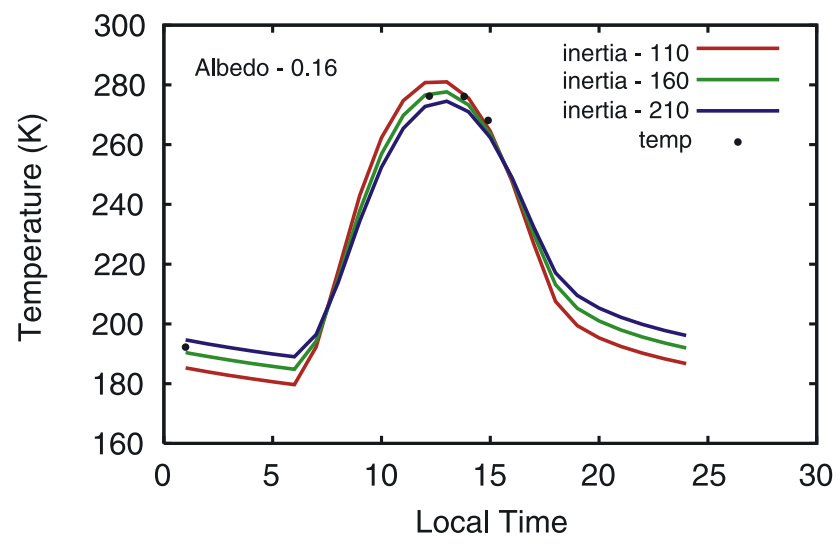

Figure 10. Diurnal temperature curves of bedforms in Bonneville crater. (a) Plot of the modeled diurnal temperature curve for the upper section of the bedform (using an opacity of 0.69 , Ls of $4.6^{\circ}$, and slope of $11.0^{\circ}$ at an azimuth of $180^{\circ}$ ) and Mini-TES target temperatures; RMS error is $2.5 \mathrm{~K}$. (b) Plot of the modeled diurnal temperature curve for the lower section of the bedform (using an opacity of 0.69 , Ls of $4.6^{\circ}$, and no slope) and Mini-TES target temperatures; RMS error is $2.3 \mathrm{~K}$.

(Figure 12a), unlike the surface material at the Gusev landing site region, implying a different aeolian environment at these two localities.

[37] The Meridiani Plains soil was observed during MER-B sols 88-91 and the thermal inertia is 100 to 150 (Figure 12b), corresponding to a particle diameter of $\sim 45 \mu \mathrm{m}$ (silt). Both the thermally derived albedo and the Pancam albedo are 0.12. In this location, a single thermal inertia does not fit the entire diurnal curve. A thermal inertia of 100 fits the data well until $\sim 15 \mathrm{H}$; a thermal inertia of 150 provides a better fit to the late afternoon data. Thus there is a phase lag in which measured temperatures cool more slowly in the afternoon than modeled temperatures. This complex behavior suggests that this surface is retaining more heat in the afternoon than the thermal model predicts and that the processes operating at this site are not adequately represented in the thermal model. One possible explanation for this behavior is a layer of bedrock close to the surface, such as that observed in the walls of Eagle and Endurance craters. This would allow the surface to retain more heat in the afternoon, and this layered subsurface would not follow model predicted diurnal behavior. However, bedrock close enough to the surface to affect the thermal inertia is expected to outcrop along the traverse, which was rarely observed. Thus this scenario is not likely. In addition, the modeled thermal inertia is lower than what is implied by MI particle size measurements as the MI observed a bimodal particle size distribution of $0.6-6 \mathrm{~mm}$ diameter particles set in fine sand $<125 \mu \mathrm{m}$ [Herkenhoff et al., 2004b]. A material consisting of vesicular, less conductive grains, such as pumice, would lower the thermal inertia relative to the MI-measured particle size. This is also unlikely since the MI-measured particle sizes correspond well with orbital thermal inertia data [Fergason and Christensen, 2003; Christensen et al., 2004b]. In light of this discussion, there is not a clear cause at this time for the discrepancy between thermally derived particle sizes and particles

(a)
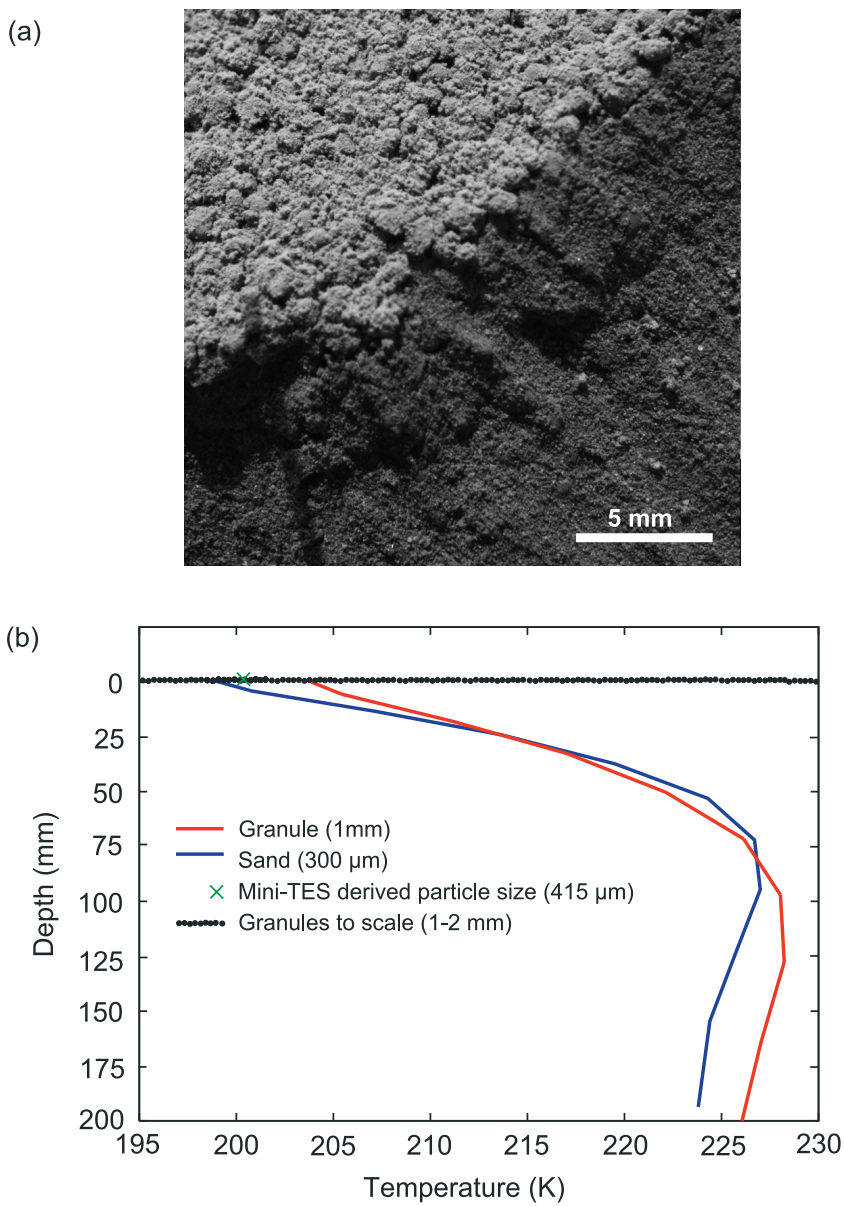

Figure 11. Serpent Bedform at Gusev crater. (a) Portion of MI image 2M132842058FFL2000P2977 (sol 073) of the disturbed bedform Serpent indicating a trimodal distribution of particle sizes of 1-2 mm (possibly bonded), 250$500 \mu \mathrm{m}$, and $<210 \mu \mathrm{m}$. (b) Plot of modeled subsurface temperature at midnight of $1 \mathrm{~mm}$ granules (bedform armor), $300 \mu \mathrm{m}$ sand grains (interior of bedform), and surface temperature of $415 \mu \mathrm{m}$ sand grains (Mini-TES-derived particle size) at midnight. The circles at the "surface" are a scale representation of the size of the bedform armor relative to the subsurface temperature waveforms. 
(a)

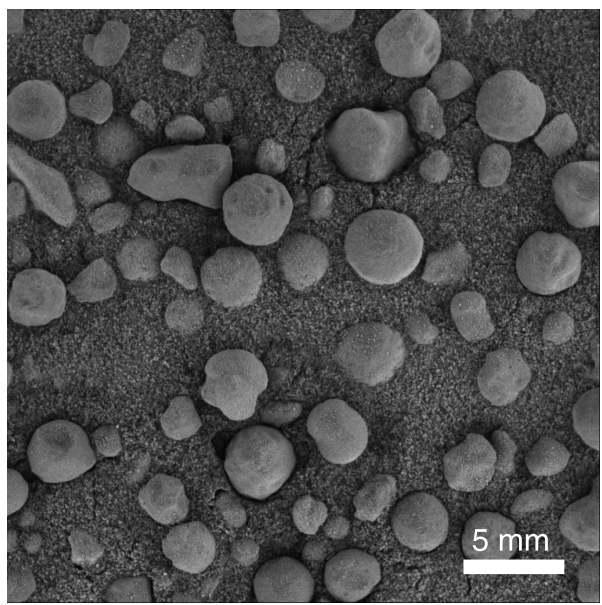

(b)

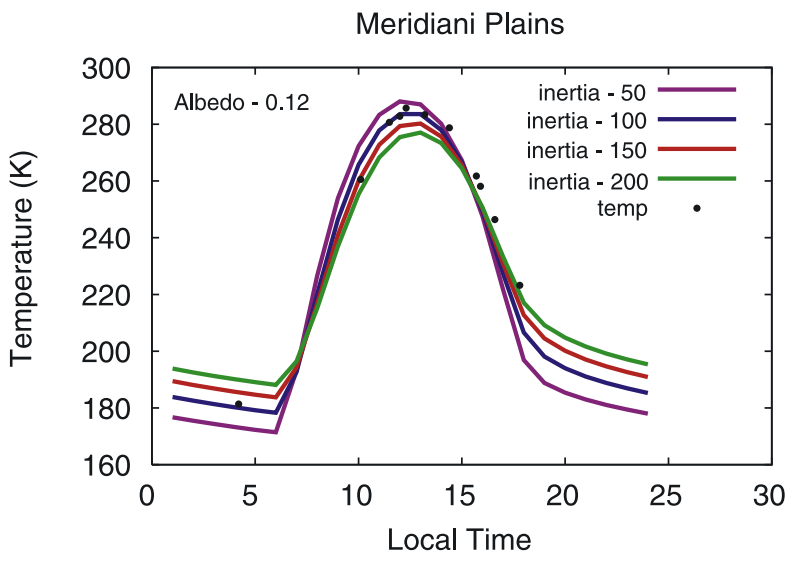

Figure 12. Meridiani Plains soil. (a) Typical example of the Meridiani Plains soil (MI image 1M133776216FFL08A6P2957, sol 063). (b) Plot of the modeled diurnal temperature curve (using an opacity of 0.63 and Ls of $24.0^{\circ}$ ) and Mini-TES target temperatures; RMS error is $6.3 \mathrm{~K}$ for an inertia of 100 and $5.9 \mathrm{~K}$ for an inertia of 150 .

measured directly using MI images at the Meridiani plains. However this is the only locality that is problematic, and particle sizes measured at other sites correspond well with those derived from thermal inertia values.

\subsubsection{Intracrater Deposits in Endurance Crater}

[38] The entire bedform located on the floor of Endurance crater has a modeled thermal inertia of 200 , corresponding to $160 \mu \mathrm{m}$ diameter particles (fine sand) (Figures 3 and 4 ). This deposit also provides an opportunity to determine if particle sizes between bedform crests and intercrest areas that fill the Mini-TES FOV can be differentiated. The temperatures vary by up to $5^{\circ} \mathrm{K}$ near noon across the bedform, but because of the large Mini-TES footprint it is difficult to correlate temperature variations with bedform morphology. These observed temperature differences are likely caused by a combination of a change in particle size from the bedform crest to trough and the differential heating caused by sloped surfaces. The aeolian material surrounding the intracrater bedform appears to be well sorted, and displays no bedform morphology. The thermal inertia of this material is 100 , corresponding to particle diameters $<45 \mu \mathrm{m}$ (silt), which is lower than the calculated thermal inertias of the bedform, and this lower particle size may explain why bedforms do not develop in this material.

[39] The thermal inertia modeled for bedforms within both Bonneville and Endurance craters $(160-200)$ is lower than the average intracrater bedform thermal inertia derived from Viking and TES orbital data $(\sim 270)$, but does fall within the range of bedform thermal inertias for intracrater deposits observed from orbit [e.g., Edgett and Christensen, 1991, 1994; Aben, 2003; Fenton et al., 2003]. In addition, Christensen [1983] noted that the average grain size of intracrater deposits often decreases with decreasing crater size; both Bonneville and Endurance are small relative to craters observed from orbit. Therefore the lower thermal inertia and grain size within these craters is expected.

[40] Edgett and Christensen [1994] observed a correlation between intracrater deposit thermal inertias and the thermal inertia of the surrounding regolith from orbit, and suggested that there may be regional-scale controls on the particle size of intracrater material. At both landing sites, the thermal inertias measured for the soil and intracrater bedforms exhibit similar values between 100 and 200, corresponding to a particle diameter of 60 to $160 \mu \mathrm{m}$ (silt to fine sand). Thus the thermal inertia of the intracrater bedforms often reflects the physical properties of the regional soil, and this observation suggests that the sediment for these bedforms may be locally derived. However, sand grains can be transported hundreds of $\mathrm{km}$ before they break into finer particles that go into suspension [Greeley and Kraft, 2001; Rogers and Christensen, 2003]. Therefore some of these materials may have originated outside the landing site regions as well. Laboratory measurements of particle-size mobility indicate that $100-150 \mu \mathrm{m}$ is the most easily moved particle size on Mars [Iversen et al., 1976; Greeley et al., 1980]. The observation that intracrater bedforms commonly observed at these locations have particle sizes overlapping this range suggests that this material was transported into the crater by wind potentially under current Martian atmospheric conditions, but that this wind is currently unable to carry these particles back out onto the plains. This could be due to the wind dynamics inside the crater, such as reverse flow off the crater wall [Greeley et al., 1974], which does not allow the particles to be transported out of the crater.

\section{Implications}

\subsection{Thermally Derived Albedo}

[41] The thermally derived albedo values are $\sim 17 \%$ smaller than the Pancam albedo values in most cases (Table 1). This lower albedo suggests that the surface is absorbing more energy than the measured Pancam albedo indicates. This discrepancy was also observed in Viking orbital data [e.g., Kieffer et al., 1977; Palluconi and Kieffer, 1981; Hayashi et al., 1995]. The Viking IRTM thermal model assumed an atmosphere whose contribution to the downwelling radiation is equal to $2 \%$ of the maximum solar isolation, and the thermally derived albedo values are often smaller than the measured bolometric albedo [Kieffer et al., 1977; Palluconi and Kieffer, 1981]. Even with the incorporation of a more complex atmosphere, including the effect of a dusty $\mathrm{CO}_{2}$ atmosphere and a sensible heat exchange with the surface [Haberle and 

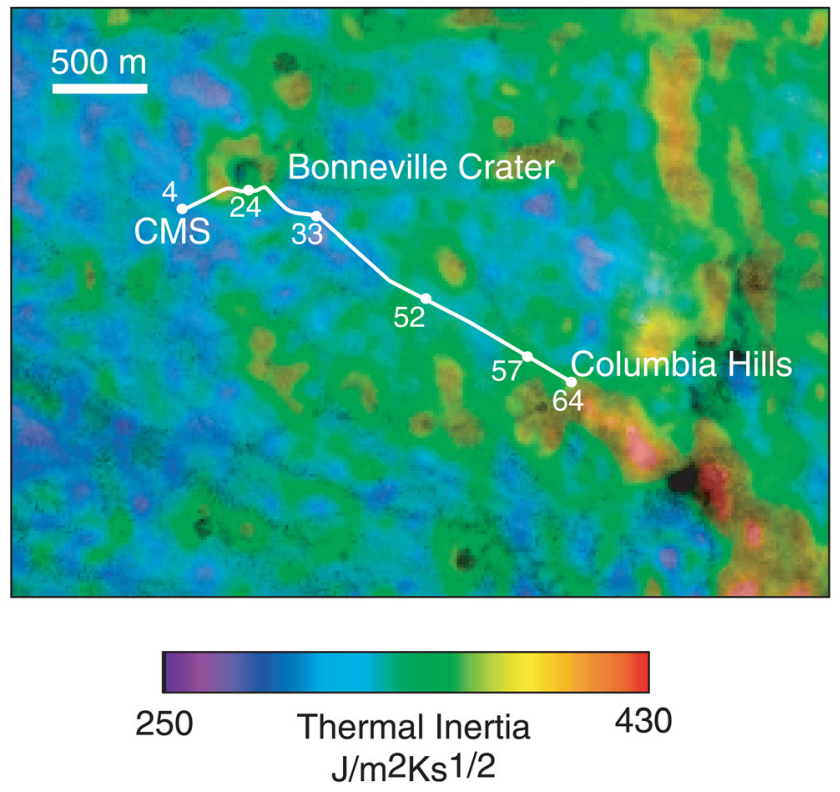

Figure 13. THEMIS thermal inertia of the Gusev landing site region. THEMIS-derived thermal inertia image overlaid onto a THEMIS visible image of the traverse from Columbia Memorial Station (CMS) to Bonneville crater to the Columbia Hills at the Gusev landing site region. Numbers indicate site positions along the traverse. Site position along the Gusev traverse was typically incremented after each drive segment and was chosen because site is more representative of the distance traveled than sol numbers.

Jakosky, 1991], the thermally derived albedo was often lower than the measured albedo values for bright surfaces and higher than the measured value for dark surfaces [Hayashi et al., 1995].

[42] Factors likely contributing to the discrepancy between thermally derived albedo values and measured bolometric albedo include thermal model uncertainties in the amount of absorbed and reflected energy (albedo) and the amount of downwelling or backscatter radiance from the atmosphere or nearby objects. Model parameters controlling atmospheric effects, such as downwelling radiance and the visible/9- $\mu \mathrm{m}$ extinction opacity ratio may be inaccurately defined because of a lack of understanding concerning atmospheric behavior. These uncertainties will affect the modeled diurnal temperature curves and thermally derived albedo that best fit the data. The visible/9- $\mu \mathrm{m}$ extinction opacity ratio may range from $\sim 2.0$ to $\sim 2.5$ for average atmospheric conditions [Clancy et al., 1995]. Uncertainties in this ratio results in $10 \%$ uncertainty $(0.5-1 \mathrm{~K}$ during the day) and this error alone is not sufficient to cause the $2.5 \mathrm{~K}$ daytime temperature difference observed for surfaces with a 0.03 difference in albedo (average difference between thermally derived albedo and Pancam albedo).

[43] The Pancam albedo assumes a Lambertian surface reflectance [Bell et al., 2006], which is not precise for most natural surfaces [e.g., Hapke, 1993, pp. 190-191]. Using the $750 \mathrm{~nm}$ band to estimate $R^{*}$ typically over-estimates the bolometric albedo (calculated using the Pancam $739 \pm$
$338 \mathrm{~nm}$ broadband filter [Bell et al., 2004a, 2004b, 2006]) by $5-10 \%$ because on average the surface reflectivity is higher at that wavelength than in the shorter wavelengths closer to the peak of the Sun's radiance spectrum. If the surface reflectance is not Lambertian, then the amount of reflectance changes with incidence and emission angle, and the measured albedo varies depending on the viewing geometry and local time of the observation [Hapke, 1993, pp. 190-192]. Therefore the albedo calculated from individual Pancam images using the $750 \mathrm{~nm}$ band may not best represent the true albedo of the surface. This uncertainty is affecting the relative difference between these two values, and is also contributing to errors in the amount of energy the model assumes is absorbed into the subsurface, which is compensated by the thermally derived albedo.

\subsection{Comparison With TES and THEMIS Orbital Data}

[44] The Thermal Emission Spectrometer (TES) [Christensen et al., 1992] and the Thermal Emission Imaging System (THEMIS) [Christensen et al., 2004a] obtain orbital thermophysical information of the Martian surface at a spatial resolution of $\sim 3 \mathrm{~km} \times \sim 6 \mathrm{~km}$ per pixel and $\sim 100 \mathrm{~m}$ per pixel respectively. The Mini-TESderived thermal inertias provide an opportunity to validate these orbital data sets, and offer insight regarding the interpretation of orbital thermal inertia data.

[45] The Spirit landing site at Gusev has an average TES thermal inertia of $\sim 290$ [Christensen et al., 2004b], suggesting that the surface is dominated by duricrust to cemented soil, noncohesive coarse sand, or a combination. This value is consistent with the variety of surface types observed by the Spirit rover. The comparison of THEMISderived thermal inertia [Fergason and Christensen, 2003] with Mini-TES thermal inertia along the traverse from the CMS to Bonneville crater and the Columbia Hills is shown in Figure 8 and Figure 13. Although the difference in resolution between the two data sets presents a challenge when comparing the resulting thermal inertia directly, inspection of THEMIS-derived thermal inertia and MiniTES thermal inertia shows that the general trends match between data sets. The thermal inertia increases along the traverse from CMS (THEMIS: $280 \pm 40$; Mini-TES: $175 \pm$ $20)$ to Bonneville crater (THEMIS: $330 \pm 50$; Mini-TES: $380 \pm 45)$ in both data sets, and is likely due to more rocky material being present as the crater ejecta material is traversed [Christensen et al., 2004a; Golombek et al., 2005]. The thermal inertia is more variable along the traverse from Bonneville crater to the Columbia Hills, but increasing and decreasing thermal inertia patterns are similar and the average value of each data set along this traverse differs by $\sim 35$ units. THEMIS thermal inertias near the Colombia Hills $(390 \pm 45)$ are larger than Mini-TES $(275 \pm 35)$ due to the incorporation of the higher-inertia hill material in the THEMIS pixel, whereas the Mini-TES is sampling surface material that excludes rocky terrain adjacent to the rover (within $\sim 1 \mathrm{~m}$ ). Generally the thermal inertia measured from the surface is lower than values observed from orbit. These lower surface thermal inertia values may indicate a data bias, as the Mini-TES observations were taken directly in front of the rover, and during the rover traverse, obstacles, such as 
Table 2. Comparison of Mini-TES-Derived Thermal Inertia, Thermally Derived Particle Sizes, and Particle Sizes Measured Directly Using MI Images ${ }^{\mathrm{a}}$

\begin{tabular}{lccc}
\hline \multicolumn{1}{c}{ Feature } & $\begin{array}{c}\text { Mini-TES-Derived } \\
\text { Thermal Inertia, } \\
\mathrm{J} / \mathrm{m}^{2} \mathrm{~K} \mathrm{~s} \mathrm{~s}^{1 / 2}\end{array}$ & $\begin{array}{c}\text { Mini-TES-Derived } \\
\text { Particle Size }\end{array}$ & $\begin{array}{c}\text { MI-Measured } \\
\text { Particle Size }\end{array}$ \\
\hline Laguna Hollow (Gusev) & 150 & $45 \mu \mathrm{m}$ & $<210 \mu \mathrm{m}$ \\
Gusev Plains Soil & $\sim 200$ & $\sim 160 \mu \mathrm{m}$ & fine grains or agglomerates of grains at the margin of resolution $(210 \mu \mathrm{m})$ \\
Serpent/Saber Bedform (Gusev) & 250 & $415 \mu \mathrm{m}$ & $\begin{array}{c}\text { trimodal: } 1-2 \mathrm{~mm}, 250-500 \mu \mathrm{m},<210 \mu \mathrm{m} \\
\text { Meridiani Plains Soil }\end{array}$ \\
\hline
\end{tabular}

${ }^{\mathrm{a}} \mathrm{MI}$ particle sizes from the Gusev landing site region are from Herkenhoff et al. [2004a]. MI particle sizes from the Meridiani landing site region are from Herkenhoff et al. [2004b].

bedforms or large rocks, were avoided. However, we now can document that there is variability and mixing of particle sizes along the traverse at Gusev crater that is not resolved in the THEMIS thermal inertia.

[46] The Meridiani plains provide a favorable opportunity to validate orbital data because the plains are uniform over several TES and THEMIS pixels. The Opportunity landing site at Meridiani has a TES thermal inertia of $\sim 200$ and a THEMIS thermal inertia of $190 \pm 30$, implying a particle size of fine sand [Golombek et al., 2005]. Orbitally derived thermal inertia values are also consistent with particle sizes estimated from Pancam and MI imagery. The Mini-TESderived thermal inertias, however, give values of 100 to 150 (Figure 12), which are lower than the orbital values, and imply particle sizes (10 to $45 \mu \mathrm{m})$ that are lower than expected for the observed bedforms. There are several potential explanations for this difference. The thermal model assumes a Lambertian visible scattering surface, where light energy is reflected equally in all directions. Results of a photometry experiment at this same location suggests a Minnaert surface, which also takes into account the viewing geometry, is a more accurate representation [Seelos et al., 2005]. The photometric properties of the surface affects the amount of absorbed energy assumed by the thermal model, and thus this parameter may not be well represented. However, it has been demonstrated that viewing sand-sized surfaces at different phase functions does not typically change the surface temperature behavior [Jakosky et al., 1990], and thus a difference in the actual surface photometry relative to what is represented in the model may not be significant. An additional possibility is that the model does not adequately account for all the surface and subsurface physical properties that are occurring at this location because the fit of modeled temperatures to those determined by Mini-TES at the Meridiani Plains has a higher RMS residual relative to other MER sites. Since TES and THEMIS both use a single-point measurement to calculate thermal inertia values, this result would not be apparent from orbital data.

\subsection{Particle Size Comparisons}

[47] Orbital thermal inertia data are commonly used to determine an effective particle size, and thus thermal inertia influences the interpretation of landforms and morphology observed from orbit. One objective of this study is to derive particle sizes from thermal inertia values and compare the results to particle sizes measured directly using MI images. This will help to validate the use of the laboratory-derived relationship between conductivity and particle size [e.g., Wechsler and Glaser, 1965; Wechsler et al., 1972; Presley and Christensen, 1997a] to estimate an effective particle size of a surface observed remotely.

[48] Coincident MI images and thermal inertia information were collected at four locations: the material filling the hollows at Gusev, the Gusev soil, the Serpent/Saber bedforms at Gusev, and the Meridiani Plains material (Table 2). The thermally derived particle sizes are often near or below the limit of MI resolution $(100 \mu \mathrm{m}$, which corresponds to a thermal inertia of $\sim 180$ ), but many of these observations are in agreement within the uncertainties of the thermal inertia calculations. In the hollows at Gusev crater, MI images revealed that the majority of the particles are at or below the $100 \mu \mathrm{m}$ limit of the MI camera. Particle sizes determined with Mini-TES (thermal inertia of 150) suggest $\sim 45 \mu \mathrm{m}$ diameter particles (silt), which is also below the resolution limit of MI. The soil along the Gusev plains is composed of very fine grains or conglomerates of grains at the margin of MI resolution [Herkenhoff et al., 2004a]. Mini-TES derives an average particle size of Gusev soil outside the hollows (thermal inertia of $\sim 200$ ) to be $\sim 160 \mu \mathrm{m}$, corresponding to fine sand, and is in agreement with MI.

[49] At the Serpent bedform in Gusev the particle size distribution measured in MI images revealed a trimodal distribution of particles $1-2 \mathrm{~mm}, 250-500 \mu \mathrm{m}$, and below $210 \mu \mathrm{m}$ [Herkenhoff et al., 2004a]. The Mini-TES-derived thermal inertia of Saber (250), a similar bedform near Serpent, suggests a particle size of $415 \mu \mathrm{m}$, which is also consistent with grains measured by the MI. Serpent and Saber probably have a layer of coarse particles that form an outer armor over finer-grained material [Greeley et al., 2004]. A single grain thickness of armor (1 - $2 \mathrm{~mm}$ particles) will increase the thermal inertia, but in this layered case the material is still dominated by the finer-grained substrate (Figure 11). Thus particle sizes derived from Mini-TES thermal inertia values and directly measured particle size distributions using MI images do compare favorably within the uncertainties in thermal inertia calculations.

[50] On the Meridiani plains, modeled temperatures did not well represent the Mini-TES target temperatures. The best-fit Mini-TES thermal inertia values of 100 to 150 indicate an average particle diameter of $<45 \mu \mathrm{m}$ (silt), which is smaller than particles capable of being measured using MI images. A bimodal particle size distribution of 0.6-6 mm particles (spherules) set in a very fine sand less than $125 \mu \mathrm{m}$ is observed with MI [Herkenhoff et al., 2004b]. Since the spherules are only a single-grain-thick layer, rather than an intimate mixture, they do not dominate the thermal inertia of this material. However, a thermal inertia of 190 corresponds to the MI observed particle size of $125 \mu \mathrm{m}$, so there is a discrepancy. The 
grains could be vesicular, which would reduce their conductivity and modeled thermal inertia relative to the particle size observed with MI. This is unlikely, however, since the MI-measured particle sizes correspond well with orbital thermal inertia data. The cause of this discrepancy is not understood. However, the results from the MER landing sites indicate that in most cases effective particle sizes derived from thermal inertia agree with directly measured size distributions, and that relationships between conductivity and particle size observed by the MER rovers are similar to that deduced in the laboratory.

\subsection{Geology and Implications}

[51] The thermal inertia along the Gusev plains traverse varies by less than 90 units, and these changes can typically be attributed to the presence of rock fragments or aeolian material in the Mini-TES FOV. Pancam images taken of the same location as the Mini-TES observations show that the variations in thermal inertia correspond with the amount of rock fragments in the area, where the number and size of rock fragments increases in higher thermal inertia regions [Ward et al., 2005]. An increase in thermal inertia and rock abundance is also associated with crater ejecta [e.g., Golombek et al., 2005, 2006]. These observations suggest that at meter scales, the thermal inertia is controlled by the abundance of drift material, rocks, and rock fragments, whose local distribution is controlled by local processes that redistribute grains and rocky material. In contrast, Christensen [1982] examined the relationship between rock abundance and the fine component thermal inertia with global thermal inertia patterns and concluded that at global scales the variations in the fine component (material less than a few $\mathrm{mm}$ ) thermal inertia, rather than the abundance of rocks, produce much of the variation in thermal inertia. These observations imply that different processes are affecting the physical surface characteristics at different scales. Rocky material from crater ejecta, presence of aeolian bedforms, and rock fragment concentrations control the thermal inertia at meter to tens of meter scales. Regional processes, such as the deposition of airfall dust, deflation or deposition of wind-blown sand, or large-scale volcanic processes, control the thermal inertia at $\mathrm{km}$ to tens of $\mathrm{km}$ scales.

[52] The rock and bedrock material on the plains and in the Columbia hills have different physical characteristics that imply that these regions have a different geologic history. The rocks on the Gusev plains are dense basalt with a thermal inertia of $\sim 1200$. At the lower Columbia Hills, however, the average thermal inertia is $\sim 620$ (maximum is $\sim 1100$ ) and suggests that Columbia Hills rocks are more weathered and friable than those found on the plains. The amount of energy per unit volume necessary to grind these rocks with the RAT instrument was also less than rocks on the plains (Gorevan et al., manuscript in preparation, 2006), supporting this interpretation. The plains rocks may be the result of a basaltic lava flow, and may have been either exhumed from the subsurface or broken into unconsolidated soil by impact events. The lower Colombia Hills rock has the physical properties of a volcaniclastic sediment, ash flow deposit, or impact debris, implying volcanic activity different from the effusion of basalt as the source for material in this region.
[53] It has been proposed that the hematite spherules are remnant lag deposit from a material that has been removed by erosion [Squyres et al., 2004b; Soderblom et al., 2004]. The lack of craters and ejecta present on the Meridiani plains also suggests that this surface has undergone extensive erosion in its history, and is in agreement with conclusions from orbital data [e.g., Christensen and Ruff, 2004; Lane et al., 2003; Hynek et al., 2002]. Further evidence for aeolian activity is found on the plains surface where aeolian bedforms are pervasive throughout the region [Sullivan et al., 2005]. Unlike Gusev, these bedforms, and those found in craters, are dark, suggesting little dust has been deposited and implying that they may be currently active or have been active in the recent past.

\section{Conclusions}

[54] The Mini-TES instrument provides the first opportunity to measure surface temperatures in-situ, derive thermal inertia values, and relate these observations to orbital results. Derived thermal inertia along the Gusev traverse and of bedforms at both sites are consistent with orbital values, and significantly improve our confidence in the accuracy and interpretation of orbital data. In addition, comparisons between thermally derived particle sizes and particle sizes measured directly using MI images imply that laboratory-derived relationships between conductivity and particle size are applicable to the surface of Mars. From this work, we conclude the following:

[55] 1. Bedforms in the floor of Bonneville crater at Gusev crater and Endurance crater at Meridiani Planum have a thermal inertia of 160 to 200 and 200, respectively, corresponding to particle diameters of $160 \mu \mathrm{m}$ (fine sand). Similar thermal inertias suggest that they formed under the same atmospheric conditions, and that particles are able to be mobile in the current climate. Bright albedo bedforms at Bonneville crater imply that these features are mantled in dust and have not been recently active. This is in contrast with bedforms observed in Endurance crater, whose dark albedo suggests recent aeolian activity.

[56] 2. In Laguna Hollow at Gusev crater, the modeled thermal inertia is 150 , which corresponds to $45 \mu \mathrm{m}$ diameter particles (silt), and is some of the finest-grained material observed at either landing site region. These small craters have been filled with a combination of fine material and air-fall dust.

[57] 3. At Gusev crater, the rock target Beacon has a thermal inertia of 1200 , which is close to that expected for a basaltic rock this size. In contrast, the rock and bedrock at the lower Columbia Hills have an average thermal inertia of $\sim 620$ (maximum value of $\sim 1100$ ). These different thermal inertia values imply that thermal inertia can differentiate between rocks of differing degrees of density or porosity. The plains rocks may be derived from a basaltic lava flow, whereas the lower Colombia Hills rocks have the physical characteristics of a volcaniclastic sediment, ash flow deposit, or impact debris.

[58] 4. Particle sizes derived from thermal inertia correspond to directly measured particle sizes using MI imagery in material filling hollows, the Gusev soil, and the Serpent/ Saber bedforms. These results suggest that techniques derived from laboratory measurement do provide a rea- 
sonable derivation of particle sizes from thermal inertia values.

[59] 5. At Gusev crater, the thermal inertia measured from the surface corresponds to trends observed from orbital data. There is variability and mixing of particle sizes on the surface that is not resolved in the orbital thermal inertia data due to meter-scale processes that are not identifiable at larger scales. On the Meridiani Plains, orbital data are consistent with visible observations in Pancam and MI imagery, but correspond poorly with Mini-TES-derived thermal inertias of 100 to 150 .

[60] 6. The diurnal temperature behavior of the Meridiani plains is not well characterized by the thermal model used in this work. In addition, the Mini-TES-derived thermal inertias are also lower than that observed with TES and THEMIS from orbit. The cause of this discrepancy is unknown at this time, but only occurs on surfaces where hematite spherules are present.

[61] 7. In most cases, the thermally derived albedo is $\sim 17 \%$ lower than the Pancam estimated bolometric albedo. This difference suggests that the surface is absorbing more energy than that predicted by the models that incorporate the measured albedo and atmospheric properties. The primary causes of this discrepancy are uncertainties in the downwelling radiance, the visible/9- $\mu \mathrm{m}$ extinction opacity ratio, and the photometric properties of the surface.

[62] Acknowledgments. We wish to thank Mark Lemmon for providing Pancam opacity data to the MER Athena Science Team. Frank Palluconi and James Zimbelman provided reviews that significantly improved the quality of this manuscript. Tim Glotch, Deanne Rogers, Steve Ruff, and Mike Wyatt also contributed discussions and suggestions that improved this work. In addition, Saadat Anwar, Noel Gorelick, and Dale Noss provided programming assistance, Mike Wyatt helped with the THEMIS overlay figure, and Jascha Sohl-Dickstein helped with calculating Pancam estimated bolometric albedo. We also wish to thank the Mini-TES, Pancam, and Microscopic Imager Mission Operations staff for collecting and calibrating the data products used in this study. This work was performed for the Jet Propulsion Laboratory, California Institute of Technology, under a contract with the National Aeronautics and Space Administration.

\section{References}

Aben, L. K. (2003), Compositional and thermophysical analysis of Martian aeolian dunes, M.S. thesis, 117 pp., Ariz. State Univ., Tempe, Dec. Arvidson, R. E., et al. (2004a), Localization and physical properties experiments conducted by Spirit at Gusev Crater, Science, 305(5685), $821-824$.

Arvidson, R. E., et al. (2004b), Localization and physical properties experiments conducted by Opportunity at Meridiani Planum, Science, 306(5702), 1730-1733

Arvidson, R. V., et al. (2006), Overview of the Spirit Mars Exploration Rover Mission to Gusev Crater: Landing site to Backstay Rock in the Columbia Hills, J. Geophys. Res., 111, E02S01, doi:10.1029/ 2005JE002499.

Bell, J. F., III, et al. (2003), Mars Exploration Rover Athena Panoramic Camera (Pancam) investigation, J. Geophys. Res., 108(E12), 8063, doi:10.1029/2003JE002070.

Bell, J. F., III, et al. (2004a), Pancam multispectral imaging results from the Spirit Rover at Gusev Crater, Science, 305(5685), 800-806.

Bell, J. F., III, et al. (2004b), Pancam multispectral imaging results from the Opportunity Rover at Meridiani Planum, Science, 306(5702), $1703-1709$.

Bell, J. F., III, J. Joseph, J. N. Sohl-Dickstein, H. M. Arneson, M. J. Johnson, M. T. Lemmon, and D. Savransky (2006), In-flight calibration and performance of the Mars Exploration Rover Panoramic Camera (Pancam) instruments, J. Geophys. Res., 111, E02S03, doi:10.1029/ 2005JE002444.

Christensen, P. R. (1982), Martian dust mantling and surface composition: Interpretation of thermophysical properties, J. Geophys. Res., 87(B12), 9985-9998.
Christensen, P. R. (1983), Eolian intracrater deposits on Mars: Physical properties and global distribution, Icarus, 56, 496-518.

Christensen, P. R. (1986), The spatial distribution of rocks on Mars, Icarus, 68, 217-238.

Christensen, P. R., and S. W. Ruff (2004), Formation of the hematitebearing unit in Meridiani Planum: Evidence for deposition in standing water, J. Geophys. Res., 109, E08003, doi:10.1029/2003JE002233.

Christensen, P. R., et al. (1992), Thermal Emission Spectrometer experiment: Mars Observer Mission, J. Geophys. Res., 97(E5), 7719-7734.

Christensen, P. R., et al. (2003), Miniature Thermal Emission Spectrometer for the Mars Exploration Rovers, J. Geophys. Res., 108(E12), 8064, doi:10.1029/2003JE002117.

Christensen, P. R., et al. (2004a), The Thermal Emission Imaging System (THEMIS) for the Mars 2001 Odyssey mission, Space Sci. Rev., 110, $85-130$.

Christensen, P. R., et al. (2004b), Initial results from the Mini-TES experiment in Gusev Crater from the Spirit Rover, Science, 305(5685), 837-842.

Clancy, R. T., S. W. Lee, G. R. Gladstone, W. W. McMillan, and T. Rousch (1995), A new model for Mars atmospheric dust based upon analysis of ultraviolet through infrared observations from Mariner 9, Viking, and Phobos, J. Geophys. Res., 100(E3), 5251-5263.

Edgett, K. S., and P. R. Christensen (1991), The particle size of Martian aeolian dunes, J. Geophys. Res., 96(E5), 22,765-22,776.

Edgett, K. S., and P. R. Christensen (1994), Mars aeolian sand: Regional variations among dark-hued crater floor features, J. Geophys. Res., 99(E1), 1997-2018.

Fenton, L. K., J. L. Bandfield, and A. W. Ward (2003), Aeolian processes in Proctor Crater on Mars: Sedimentary history as analyzed from multiple data sets, J. Geophys. Res., 108(E12), 5129, doi:10.1029/2002JE002015.

Fergason, R. L., and P. R. Christensen (2003), Thermal inertia using THEMIS infrared data, Lunar Planet. Sci. [CD-ROM], XXXIV, Abstract 1785 .

Fountain, J. A., and E. A. West (1970), Thermal conductivity of particulate basalt as a function of density in simulated lunar and Martian environments, J. Geophys. Res., 75(20), 4063-4069.

Golombek, M. P., et al. (2005), Assessment of Mars Exploration Rover landing site predictions, Nature, 436, doi:10.1038/nature03600.

Golombek, M. P., et al. (2006), Geology of the Gusev cratered plains from the Spirit rover transverse, J. Geophys. Res., 111, E02S07, doi:10.1029/ 2005JE002503.

Grant, J. A., et al. (2004), Surficial deposits at Gusev Crater along Spirit Rover traverses, Science, 305, 807-810.

Greeley, R., and M. D. Kraft (2001), Survivability of aggregate sands on Mars, Lunar Planet. Sci. [CD-ROM], XXXII, Abstract 1839.

Greeley, R., J. D. Iversen, J. B. Pollack, N. Udovich, and B. White (1974), Wind tunnel studies of Martian aeolian processes, Proc. R. Soc. London, Ser. $A, 341,331-360$.

Greeley, R., R. Leach, B. White, J. Iversen, and J. Pollack (1980), Threshold windspeeds for sand on Mars: Wind tunnel simulations, Geophys. Res. Lett., 7(2), 121-124.

Greeley, R., et al. (2004), Wind-related processes detected by the Spirit Rover at Gusev Crater, Science, 305(5685), 810-821.

Greeley, R., et al. (2006), Gusev crater: Wind-related features and processes observed by the Mars Exploration Rover Spirit, J. Geophys. Res., 111, E02S09, doi:10.1029/2005JE002491.

Haberle, R. M., and B. M. Jakosky (1991), Atmospheric effects on the remote determination of thermal inertia on Mars, Icarus, 90, 187204.

Hapke, B. (1993), Theory of Reflectance and Emittance Spectroscopy, 455 pp., Cambridge Univ. Press, New York.

Hayashi, J. N., B. M. Jakosky, and R. M. Haberle (1995), Atmospheric effects on the mapping of Martian thermal inertia and thermally derived albedo, J. Geophys. Res., 100(E3), 5277-5284.

Herkenhoff, K. E., et al. (2003), Athena Microscopic Imager investigation, J. Geophys. Res., 108(E12), 8065, doi:10.1029/2003JE002076.

Herkenhoff, K. E., et al. (2004a), Textures of the soils and rocks at Gusev Crater from Spirit's Microscopic Imager, Science, 305(5685), $824-826$.

Herkenhoff, K. E., et al. (2004b), Evidence from Opportunity's Microscopic Imager for water on Meridiani Planum, Science, 306(5702), $1727-1730$.

Hynek, B. M., R. E. Arvidson, and R. J. Phillips (2002), Geologic setting and origin of Terra Meridiani hematite deposit on Mars, J. Geophys. Res., 107(E10), 5088, doi:10.1029/2002JE001891.

Iversen, J. D., J. B. Pollack, R. Greeley, and B. R. White (1976), Saltation threshold on Mars: The effect of interparticle force, surface roughness, and low atmospheric density, Icarus, 29, 381-393.

Jakosky, B. M. (1979), The effects of nonideal surfaces on the derived thermal properties of Mars, J. Geophys. Res., 84(B14), 8252-8262. 
Jakosky, B. M. (1986), On the thermal properties of Martian fines, Icarus, $66,117-124$

Jakosky, B. M., G. W. Finiol, and B. G. Henderson (1990), Directional variations in thermal emission from geologic surfaces, Geophys. Res. Lett., $17(7), 985-988$.

Jakosky, B. M., M. T. Mellon, H. H. Kieffer, P. R. Christensen, E. S. Varnes, and S. W. Lee (2000), The thermal inertia of Mars from the Mars Global Surveyor Thermal Emission Spectrometer, J. Geophys. Res., 105, 9643-9652.

Kahle, A. B. (1980), Surface thermal properties, in Remote Sensing in Geology, edited by B. S. Siegal and A. R. Gillespie, pp. 257-273, John Wiley, Hoboken, N. J.

Kieffer, H. H., S. C. Chase Jr., E. Miner, G. Münch, and G. Neugebauer (1973), Preliminary report on infrared radiometric measurements from the Mariner 9 spacecraft, J. Geophys. Res., 78(20), 4291-4312.

Kieffer, H. H., T. Z. Martin, A. R. Peterfreund, B. M. Jakosky, E. D. Minert, and F. D. Palluconi (1977), Thermal and albedo mapping of Mars during the Viking primary mission, J. Geophys. Res., 82(28), 4249-4291.

Kieffer, H. H., B. M. Jakosky, and C. W. Snyder (1992), The planet Mars From antiquity to the present, in Mars, edited by H. H. Kieffer et al., pp. 1-33, Univ. of Ariz. Press, Tucson.

Lane, M. D., P. R. Christensen, and W. K. Hartmann (2003), Utilization of the THEMIS visible and infrared imaging data for crater population studies of the Meridiani Planum landing site, Geophys. Res. Lett., 30(14), 1770, doi:10.1029/2003GL017183.

Lemmon, M. T., et al. (2004), Atmospheric imaging results from the Mars Exploration Rovers: Spirit and Opportunity, Science, 306(5702), $1753-$ 1756.

Mellon, M. T., B. M. Jakosky, H. H. Kieffer, and P. R. Christensen (2000), High-resolution thermal inertia mapping from the Mars Global Surveyor Thermal Emission Spectrometer, Icarus, 148, 437-455.

Moersch, J. E., et al. (2005), Comparison of orbital infrared observations and surface measurements by the Mars Exploration Rover Spirit at Gusev Crater, Lunar Planet. Sci. [CD-ROM], XXVI, Abstract 2020.

Neugebauer, G., G. Münch, H. Kieffer, S. C. Chase Jr., and E. Miner (1971), Mariner 1969 infrared radiometer results: Temperatures and thermal properties of the Martian surface, Astron. J., 76(8), 719728.

Palluconi, F. D., and H. H. Kieffer (1981), Thermal inertia mapping of Mars from $60^{\circ} \mathrm{S}$ to $60^{\circ} \mathrm{N}$, Icarus, $45,415-426$.

Pollack, J. B., D. S. Colburn, F. M. Flasar, R. Kahn, C. E. Carlston, and D. Pidek (1979), Properties and effects of dust particles suspended in the Martian atmosphere, J. Geophys. Res., 84(B6), 2929-2945.

Presley, M. A., and P. R. Christensen (1997a), Thermal conductivity measurements of particulate materials: 2. Results, J. Geophys. Res. 102(E3), 6551-6566.

Presley, M. A., and P. R. Christensen (1997b), The effect of bulk density and particle size sorting on the thermal conductivity of particulate materials under Martian atmospheric pressures, J. Geophys. Res., 102(E4), 9221-9229.

Reid, R. J., et al. (1999), Imager for Mars Pathfinder (IMP) image calibration, J. Geophys. Res., 104(E4), 8907-8925.

Robertson, E. C., and D. L. Peck (1974), Thermal conductivity of vesicular basalt from Hawaii, J. Geophys. Res., 79(32), 4875-4888.
Rogers, D., and P. R. Christensen (2003), Age relationship of basaltic and andesitic surface composition on Mars: Analysis of high-resolution TES observations in the northern hemisphere, J. Geophys. Res., 108(E4), 5030, doi:10.1029/2002JE001913.

Ruff, S. W., and P. R. Christensen (2002), Bright and dark regions on Mars: Particle size and mineralogical characteristics based on Thermal Emission Spectrometer data, J. Geophys. Res., 107(E12), 5127, doi:10.1029/ 2001JE001580.

Seelos, F. P., R. E. Arvidson, E. A. Guinness, M. J. Wolff, and the Athena Science Team (2005), Radiative transfer photometric analysis at the Mars Exploration Rover landing sites, Lunar Planet. Sci. [CD-ROM], XXVI, Abstract 2054

Smith, D. E., and M. T. Zuber (1998), The relationship between MOLA northern hemisphere topography and the $6.1-\mathrm{mbar}$ atmospheric pressure surface of Mars, Geophys. Res. Lett., 25(24), 4397-4400.

Smith, D. E., et al. (2001), Mars Orbiter Laser Altimeter: Experiment summary after the first year of global mapping of Mars, J. Geophys. Res., 106(E10), 23,689-23,722.

Soderblom, L. A., et al. (2004), Soils of Eagle Crater and Meridiani Planum at the Opportunity Rover landing site, Science, 306(5702), 1723-1726.

Squyres, S. W., et al. (2004a), The Spirit Rover's Athena science investigation at Gusev Crater, Mars, Science, 305(5685), 794-799.

Squyres, S. W., et al. (2004b), The Opportunity Rover's Athena science investigation at Meridiani Planum, Mars, Science, 306(5702), $1698-$ 1703.

Sullivan, R., et al. (2005), Aeolian processes at the Mars Exploration Rover Meridiani Planum landing site, Nature, 436, doi:10.1038/nature03641.

Toon, O. B., J. B. Pollack, and C. Sagan (1977), Physical properties of the particles comprising the Martian dust storm of 1971-1972, Icarus, 3, $633-696$

Wang, A., et al. (2006), Sulfate deposition in subsurface regolith in Gusev Crater, Mars, J. Geophys. Res., doi:10.1029/2005JE002513, in press.

Ward, J. G., R. E. Arvidson, and M. Golombek (2005), The size-frequency and areal distribution of rock clasts at the Spirit landing site, Gusev crater, Mars, Geophys. Res. Lett., 32, L11203, doi:10.1029/2005GL022705.

Wechsler, A. E., and P. E. Glaser (1965), Pressure effects on postulated lunar materials, Icarus, 4, 335-352.

Wechsler, A. E., P. E. Glaser, and J. A. Fountain (1972), Thermal properties of granulated materials, in Thermal Characteristics of the Moon, edited by J. W. Lucas, Progr. Astron. Aeronaut., 28, 215-241.

Zimbelman, J. R. (1986), The role of porosity in thermal inertia variations on basaltic lavas, Icarus, 68, 366-369.

J. F. Bell III, Department of Astronomy, Space Science Building, Cornell University, Ithaca, NY 14853, USA.

P. R. Christensen and R. L. Fergason, Department of Geological Sciences, Arizona State University, Box 876305, Tempe, AZ 85287-6305, USA. (robin.fergason@asu.edu)

M. P. Golombek, Jet Propulsion Laboratory, California Institute of Technology, 4800 Oak Grove Drive, Pasadena, CA 91109, USA.

K. E. Herkenhoff, Astrogeology Team, U.S. Geological Survey, 2255 North Gemini Drive, Flagstaff, AZ 86001, USA.

H. H. Kieffer, Celestial Reasonings, Carson City, NV 89703, USA. 